\title{
Studi Termodinamika Transpor Ionik Natrium Klorida Dalam Air dan Campuran Tertentu
}

\author{
Rahmi Hidayati ${ }^{1}$, Rahadian Zainul ${ }^{2}$ \\ ${ }^{1}$ Student Chemistry Education, FMIPA, State University of Padang \\ ${ }^{2}$ Physical Chemistry Education, FMIPA, State University of Padang \\ Email : ${ }^{1}$ rahmihidayati540@gmail.com \\ 2rahadianzmsiphd@yahoo.com
}

\begin{abstract}
Abstrak. Natrium klorida dikenal dengan garam dapur. Senyawa ini memiliki rumus $\mathrm{NaCl}$ dan larut dalam air. Natrium klorida merupakan senyawa yang berwujud padat bentuk kristal dan berwarna putih. Natrium klorida merupakan senyawa ionik karena adanya ikatan antara logam natrium dengan non logam klorin. Natrium klorida, didalam air dapat terion menjadi ion ion penyusunnya. Penulisan review ini bertujuan untuk menganalisis interaksi molekul pada $\mathrm{NaCl}$ yang dilarutkan dalam air. Metode yang digunakan dalam menganalisis interaksi molekul adalah dengan permodelan menggunakan aplikasi ChemDraw 3D. Sedangkan untuk parameter mobilitas ion, konduktivitas, viskositas, dan konduktivitas molar digunakan perhitungan dan data dari salah satu jurnal yang telah di review. Penggunaan ChemDraw 3D dan ChemDraw 2D sebagai langkah untuk menganalisis atom atom penyusun $\mathrm{NaCl}$ beserta molekul dan pergerakan molekulnya. Hasil yang didapatkan yaitu struktur natrium klorida dengan analisis molekular 2D dan 3D. Analisis jari-jari natrium klorida pada Chemdraw 3D didapatkan sebesar 2,530A, dan jari jari atom natrium dan klor masing-masingnya sebesar 1.287A dan 1.688A. Setelah dilakukan optimasi MMFF94, didapatkan energi sterik sebesar $0.00073874 \mathrm{kcal} / \mathrm{mol}$ dan energi molekul bergerak dalam 30 interaksi atomnya adalah $101,4 \mathrm{kcal} / \mathrm{mol}$. Natrium klorida mempunyai beberapa sifat termokimia dalam fasa padat pada tekanan $1 \mathrm{~atm}$ dan suhu $25^{\circ} \mathrm{C} \quad \Delta \mathrm{Gf}^{\circ}$ 411.2, $\mathrm{kj} / \mathrm{mol}, \Delta \mathrm{Hf}^{\circ} \quad-384.1 \mathrm{~S}^{\circ} 72.1 \mathrm{dan} \mathrm{C} 50.5$. Mobilitas ion natrium sebesar $5,19 \mathrm{~m}^{2} \mathrm{~s}^{-1} \mathrm{~V}^{-1}$ dan mobilitas ion klorin bernilai $7,91 \mathrm{~m}^{2} \mathrm{~s}^{-1} \mathrm{~V}^{-1}$.
\end{abstract}

Kata Kunci : Natrium klorida,Interaksi Molekul,Konduktivitas,Mobilitas ion.

\section{PENDAHULUAN}

Di alam, $\mathrm{NaCl}$ tersebar merata. Air laut ${ }^{(18 ; 19)}$ mengandung $1-5 \%$ Natrium Klorida. Selain itu, Garam murni dapat ditemukan dalam garam halite ${ }^{(20-22)}$ /garam batu. Untuk mendapatkan produk natrium klorida yang berasal dari laut, biasanya dilakukan proses penguapan ${ }^{(23-25)}$.

Natrium Klorida mempunyai ikatan ionik yang terbentuk karena kecenderungan atom ${ }^{(26-30)}$ menangkap/ melepas elektron ${ }^{(31-36)}$ agar tercapai kongfigurasi gas mulia. Natrium sebagai atom logam ${ }^{(37 ; 38)}$ cenderung melepaskan elektron $^{(39-43)}$ dan menjadi ion positif ${ }^{(44-48)}$ sedangkan atom klorin,cenderung menagkap elektron dan menjadi ion negatif. Natrium memiliki nomor atom 11, untuk stabil, natrium melepaskan 1 elektron pada kulit terluarnya. Sedangkan 
klorin memiliki nomor atom 17, untuk stabil klorin menangkap 1 elektron dari atom lain. sehingga, jika natrium dengan klor berikatan, akan terjadi serah terima elektron yang menyebabkan mereka berikatan ${ }^{(49-52)}$ ionik.

\begin{tabular}{|ccc|}
\hline $\mathrm{K}$ & $\mathrm{L}$ & $\mathrm{M}$ \\
2 & 8 & 1 \\
\hline
\end{tabular}$\quad$\begin{tabular}{lll|}
$\mathrm{K}$ & $\mathrm{L}$ & $\mathrm{M}$ \\
2 & 8 & 7 \\
\hline
\end{tabular}

Gambar 1. Konfigurasi $\mathrm{Na}$ (kation) dan $\mathrm{Cl}$ (anion)

Sederhananya dapat digambarkan sebagai berikut
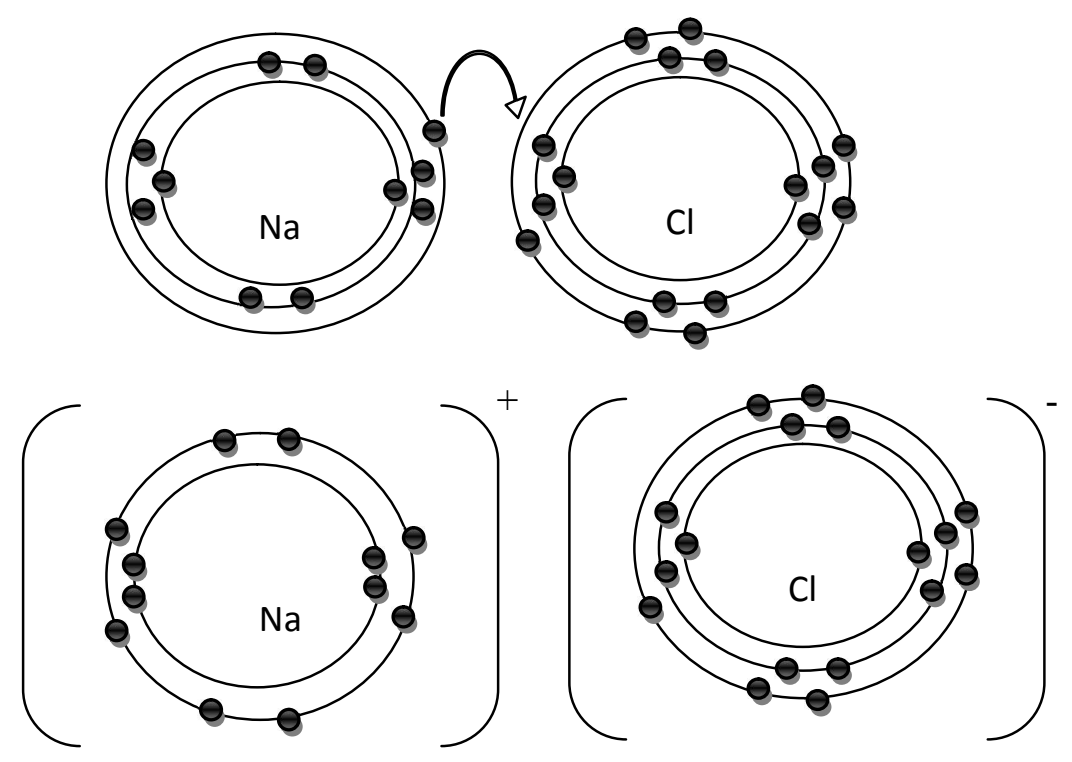

Gambar 2. Ikatan ionik pada $\mathrm{NaCl}$

Ada dua atom penyusun $\mathrm{NaCl}$ yaitu natrium dan klor. Natrium merupakan logam ${ }^{(71-73)}$ lunak yang sangat reaktif dengan warna keperakan. Karena kereaktifannya, natrium disimpan pada minyak atau gas innert sehingga tidak dapat bereaksi dengan oksigen pada udara. Natrium merupakan konduktor listrik dan panas yang baik, karena hanya memilki 1 elektron pada kelopak valensinya, sehingga menghasilkan ikatan ogam yang lemah. Atom natrium ${ }^{(74-81)}$ memiliki 11 elektron, lebih banyak satu elektron daripada gas neon yang stabil. Oleh karena itu,atom natrium lebih mudah kehilangan elektron pada kulit terluarnyadan menjadi bermuatan positif dari pada menjadi bermuatan negatif. Oleh karena itu, energi ionisas ${ }^{\mathrm{i}(82-86)}$ pertamanya cukup rendah yaitu pada 495,8 $\mathrm{kj} / \mathrm{mol}$. Sebaliknya, energi ${ }^{(87-91)}$ ionisasi $^{(92-101)}$ kedua sangat tinggi $(4562 \mathrm{kj} / \mathrm{mol})$, karna elektron pada kulit $\mathrm{L}$ lebih dekat ke ini atom. Akibatnya, natrium membentuk senyawa ionik ${ }^{(48)}$ dengan bermuatan $\mathrm{Na}^{+}$. Titik lebur $\left(98^{\circ} \mathrm{C}\right)$ dan didih $\left(883^{\circ} \mathrm{C}\right)$ natrium lebih rendah daripada litium tetapi lebih tinggi daripada logam alkali yang lebih berat (kalium $^{(102-111)}$, rubidium ${ }^{(112-114)}$, dan sesium ${ }^{(115)}$ ), mengikuti tren periodik sepanjang golongan dari atas ke bawah. Atom penyusun $\mathrm{NaCl}$ lainnya adalah klorin. Klorin berwujud gas, dan berwarna kuning-kehijauan 
pada suhu kamar. Unsur ${ }^{(116-120)}$ ini adalah unsur ${ }^{(121-125)}$ yang sangat reaktif dan oksidator kuat akibat afinitas elektron dan elektronegativitas yang tinggi.

Ada beberapa cara untuk mensintesis garam dapur. Pertama, dapat digunakan metode kristalisasi. Metode ini didasarkan pada perbedaaan daya kelarutan $^{(126-130)}$ antar zat yang dimurnikan dengan zat lain dalam suatu pelarut tertentu. Ada beberapa syarat suatu pelarut dapat dipakai dengan proses ekstraksi yaitu ada perbedaan kelarutan yang besar antara zat yang dimurnikan dengan zat pengotor, mudah di pisahkan dari kristal, dan tidak mudah bereaksi dengn kristal. Natrium klorida biasanya mengandung pengotor berupa ion ion. Agar daya larut $\mathrm{NaCl}$ dengan pengotor cukup besar, maka perlu dilakukan penambahan zat-zart tertentu yang akan membentuk senyawa garam sukr larut dalam air. Penambahan zat pengikat pengotor akan menyebabkan interaksi antara zat pengotor dengan pengotor yang akan mengendap. Selain cara ini, kristalisasi juga dapat dilakukan dengan cara membuat larutan jenuh dengan menambahkan ion sejens ke dalam larutan zat yang akan dipisahkan. Tahap pertama dilakukan pelaruatan $\mathrm{NaCl}$ kedalam air, kemudian ditambahkan zat pengotor seperti natrium karbonat atau natrium oksalat, lalu disaring. Setelah didapatkan filtrat,dilakukan pemanasan sebagai upaya menguapkan semua air yang terdapat dalam filtrat. Rekristalisasi dibutuhkan jika garam yang dihasilkan belum murni/masih ada zat pengotor. Selain kristalisasi, dapat digunakan pemurnian garam menggunakan metode hidroekstraksi. Dengan mencuci kristal garam dengan larutan garam jenuh dan di ekstraksi.

Natrium klorida memiliki konduktivitas listrik, yang besarnya ditentukan oleh beberapa faktor seperti konsentrasi lautan. Semakin encer suatu larutan, semakin besar konduktivitas dari larutan. Hal ini disebabkan karena ion ion yang terdapat dalam larutan lebih bebas bergerak. Arus listrik yang terjadi disebabkan karena adanya pergerakan dari ion ion tersebut.

Natrium klorida mempunyai beberapa sifat termokimia dalam fasa padat. Pada tekanan ${ }^{[222]}$ sebesar $1 \mathrm{~atm}$ dan suhu sebesar $25^{\circ} \mathrm{C}$, nilai dari termokimia natrium klorida yaitu $\Delta \mathrm{Gf}^{\circ}-411.2 \mathrm{kj} / \mathrm{mol}, \Delta \mathrm{Hf}^{\circ}-384.1, \mathrm{~S}^{\circ} 72.1$ dan C 50.5.

Penelitian ini bertujuan untuk mengetahui interaksi pada molekul pada natrium klorida serta pergerakan molekul natrium klorida. Kemudian digunakan sebagai analisis jari-jari ${ }^{(131-135)}$ atom penyusunnya dengan menggunakan ChemDraw $3 D$ serta digunakan untuk menganalisis sifat sifat khusus dari natrium klorida.

\section{METODOLOGI}

Metode yang digunakan dalam penelitian adalah penggambaran molekul melalui aplikasi ChemDraw $3 D$ dan aplikasi ChemDraw 2D, penelusuran literatur dengan Endnote X7 dan perhitungan matematis.

Pada penggambaran molekul, ada beberapa tahap penilaian yang dilakukan,yaitu (1) analisis molekul $\mathrm{NaCl}$ menggunakan ChemDraw 3D, (2) analisis molekul $\mathrm{NaCl}$ menggunakan ChemDraw 2D. hal yaitu,

Analisis molekul $\mathrm{NaCl}$ menggunakan ChemDraw 3D dilakukan beberapa

a. Menghitung pergerakan molekul menggunakan MMFF94 dari molekul yang terdiri dari MFF94 minimization, MMFF94 molekular dynamic, dan MMFF94 energy and gradient.

b. Menghitung jari-jari atom natrium dan atom klorida. 
c. Menganalisis bentuk molekul pada pelarut air menggunakan Solvent Accesible $^{(136)}$

Molekul $\mathrm{NaCl}$ digambarkan menggunakan software dari Chemdraw Ultra dengan cara pilih Structure kemudian Convert Name To Structure. Selanjutnya ketik $\mathrm{NaCl}$ pada layar yang muncul, tekan $\mathrm{OK}$. Struktur 2D senyawa $\mathrm{NaCl}$ akan muncul. Proses analisis menggunakan View, kemudian Show Analysis Window dan Show Chemical Properties Windows.

Molekul $\mathrm{NaCl}$ dapat dianalisis struktur 3D dengan mengcopy molekul yang terbentuk pada ChemDraw 2D ke ChemDraw Bio 3D, akan langsung terbentuk molekul 3 dimensi dari $\mathrm{NaCl}$. Selanjutnya, dilakukan penghitungan MMFF94 dengan cara Calculate pada toolbar, ambil MMFF94, kemudian pilih minimization, molekular dynamic dan energy and gradient. Pengukuran jari jari atom, menggunakan analysis MM2 pada calculate, pilih MM2 kemudian ambil Show Properties.

Molekul $\mathrm{NaCl}$ dapat dianalisis Surface molekulnya yaitu Surface Solvent Accesible dan Surface Connolly Molekular dengan tipe yang digunakan yaitu solid, wire mesh, and tranculent.

Dalam penelusuran literatur, digunakan aplikasi EndNote X7. Penggunaan aplikasi ini menggunakan sambungan internet. Untuk mendapatkan literatur yang berhubungan dengan konten pada paper, di masukan kata/kalimat dalam pencarian. Pastikan kata rujukan All field dan perpustakaan yang terhubung adalah PubMed. Rujukan literatur akan diproses dan dapat disitasi pada paper. 


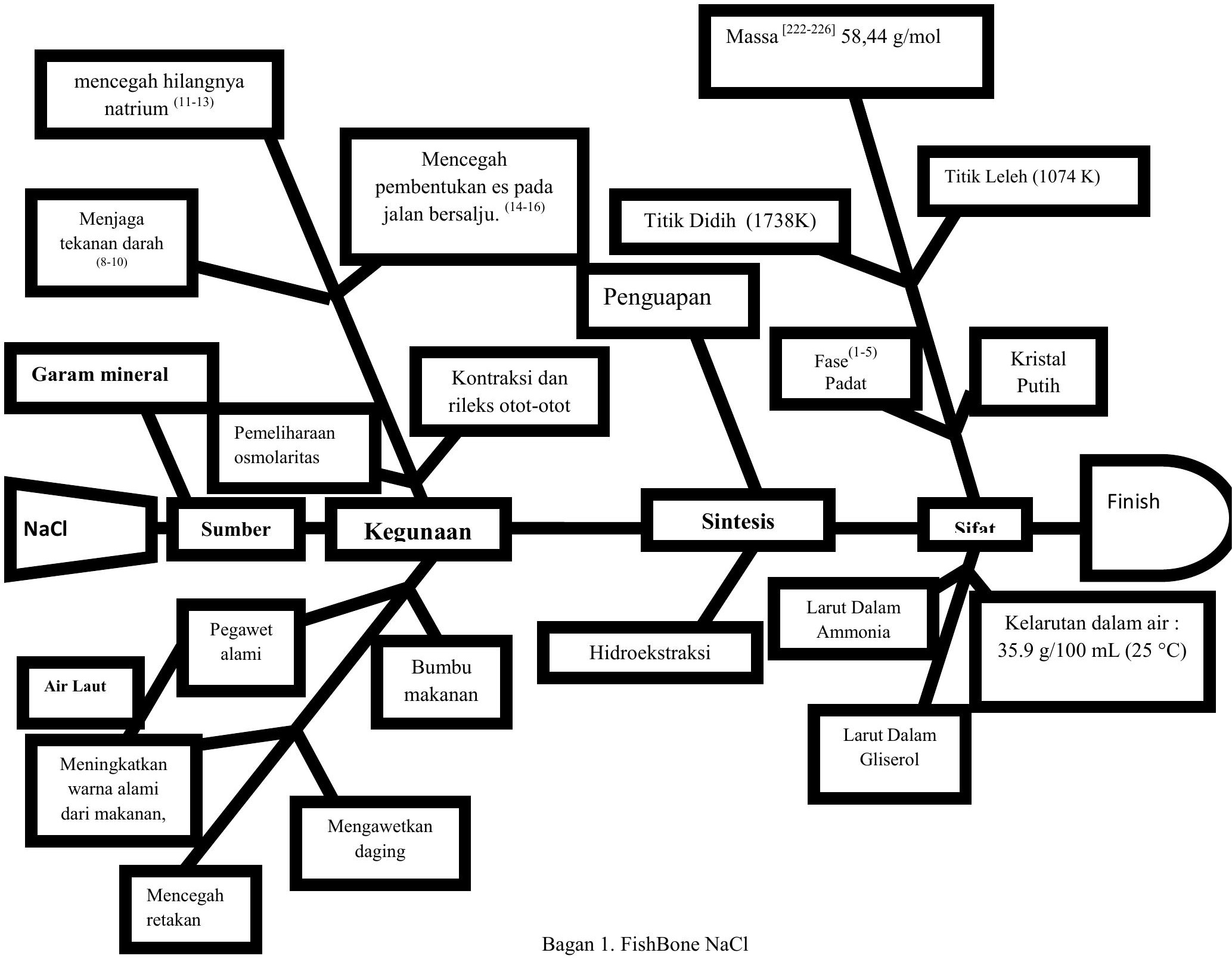

3. PEMBAHASAN

1. Sifat Natrium Klorida

\begin{tabular}{cc}
\hline Sifat Fisika & Data \\
\hline Massa Molar ${ }^{(137-139)}$ & $58,44 \mathrm{~g} / \mathrm{mol}$ \\
Penampilan & Berbentuk kristal putih \\
Densitas $^{(140-142)}$ & $2,16 \mathrm{~g} / \mathrm{cm}^{3}$ \\
Titik Lebur $^{(143-145)}$ & $801^{\circ} \mathrm{C}(1074 \mathrm{~K})$ \\
Titik Didih $^{(146-148)}$ & $1465^{\circ} \mathrm{C}(1738 \mathrm{~K})$ \\
Kelarutan $^{(149-151)}$ Dalam Air & \\
\hline
\end{tabular}


Natrium klorida memiliki bentuk kristal berwarna putih dengan struktur kristal $^{(155-159)}$ adalah kubus yang berpusat pada wajah. Natrium klorida dapat terion $^{(17)}$ dalam air ${ }^{(160)}$ jika dilarutkan dengan perbandingan pelarut yang lebih banyak.

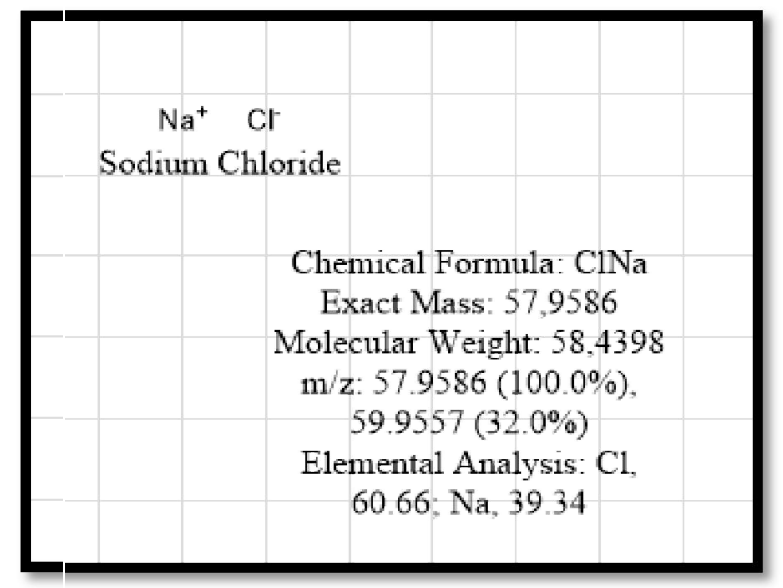

Gambar 3. Analisis molekul NaCl menggunakan ChemDraw Ultra (Chemoffice 2D Version 15, Perkinelmer Informatic. Inc, 2015)

Termokimia terbagi atas 2 bagian yaitu entropi molar standar dan entalpi molar standar. Entropi molar standar adalah entropi satu mol zat pada keadaan standar $\left(\mathrm{T}=25^{\circ} \mathrm{C}\right.$ dan $\left.\mathrm{P}=1 \mathrm{~atm}\right)$. Biasanya, entropi molar standar disimbolkan dengan $\mathrm{S}^{\circ}$. sedangkan perubahan entalpi ${ }^{[232-236]}$ pembentukan standar adalah perubahan entalpi 1 mol senyawa dari elemen elemen senyawa tersebut dalam keadaan standar.

Ada istilah lain dalam termokimia yaitu energi bebas gibbs yang menyertai pembentukan $1 \mathrm{~mol}$ zat dari atom penyusunnya dalam keadaan standar. Energi bebas gibs diberi simbol $\Delta \mathrm{G}^{\circ} \mathrm{f}$. Semua unsur ${ }^{[237-238]}$ dalam keadaan standarnya memiliki nilai energi bebas Gibbs pembentukan standar sama dengan nol, seperti tidak ada perubahan yang terlibat. Energi bebas gibbs dapat sebagai penentu sebuah reaksi berjalan spontan atau tidak spontan dengan perhitungan berikut

$$
\Delta G=\Delta H-T \Delta S
$$

Tabel 1. Termodinamika NaCl

\begin{tabular}{lcccc}
\hline Name & $\mathbf{\Delta f H}^{\circ} \mathbf{k J} / \mathbf{m o l}$ & $\mathbf{\Delta f G}^{\circ} \mathbf{k J} / \mathbf{m o l}$ & $\mathbf{S}^{\circ} \mathbf{J} / \mathbf{m o l ~ K}$ & $\mathbf{C p ~ J / m o l ~ K}$ \\
\hline ClNa Sodium chloride & -411.2 & -384.1 & 72.1 & 50.5
\end{tabular}

\section{Bentuk Molekul}

Natrium klorida $(\mathrm{NaCl})$ terdiri dari atom $\mathrm{Na}$ dan atom $\mathrm{Cl}$. Natrium merupakan golongan alkali. Berdasarkan konfigurasinya ${ }^{(57-61)}$, natrium memiliki 1 elektron ${ }^{(36)}$ valensi. Sedangkan Clor merupakan golongan halogen. Berdasarkan konfigurasinya memiliki 7 elektron valensi. Natrium dengan Clor berikatan ${ }^{(49-52)}$ ionik $^{(161-163)}$ membentuk senyawa $\mathrm{NaCl}$. 


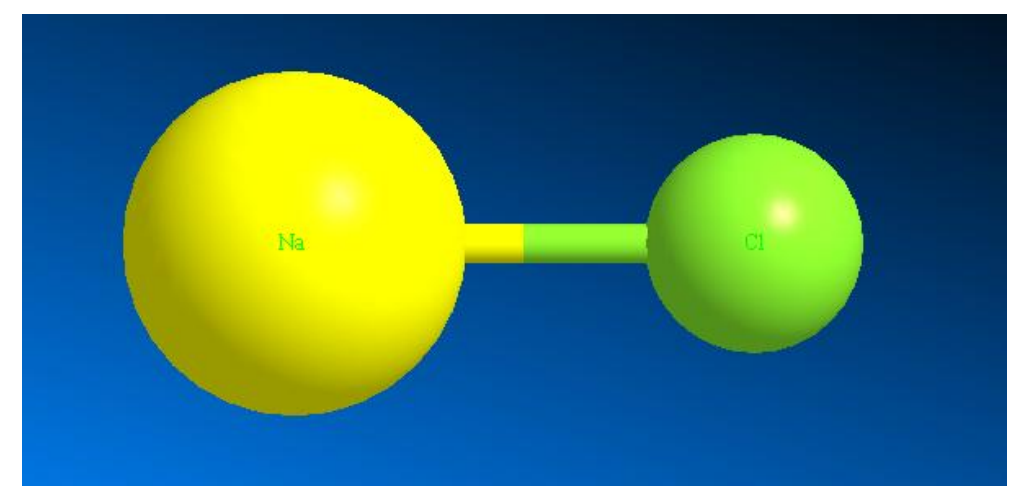

Gambar.4 Analisis 3D menggunakan ChemDraw 3D ( 2,530A) (Chemoffice 3D Version 15, Perkinelmer Informatic. Inc, 2015)

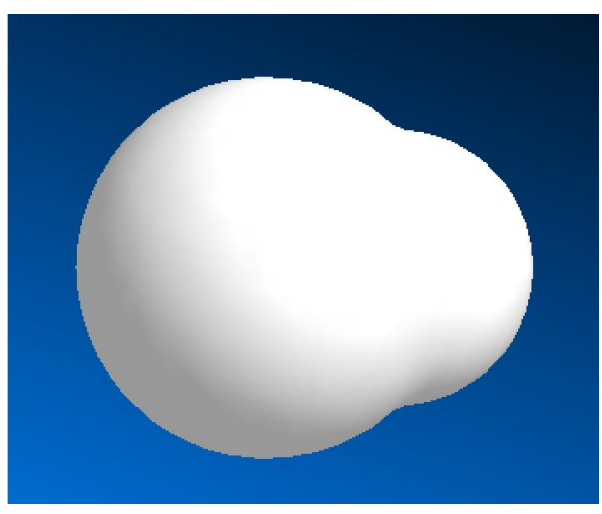

(a)

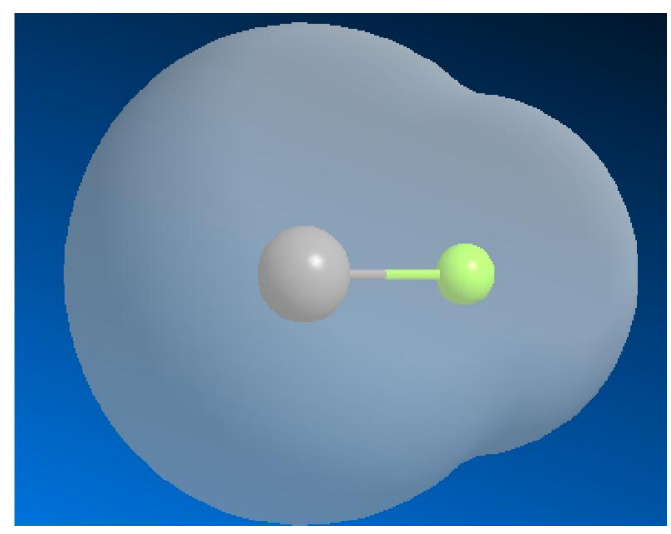

(c)

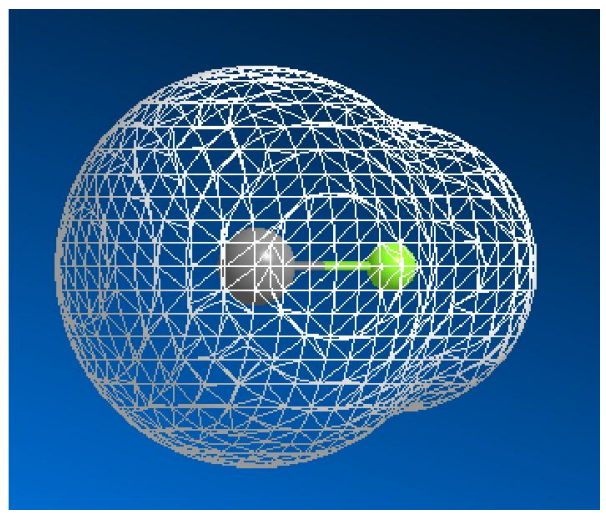

(b)

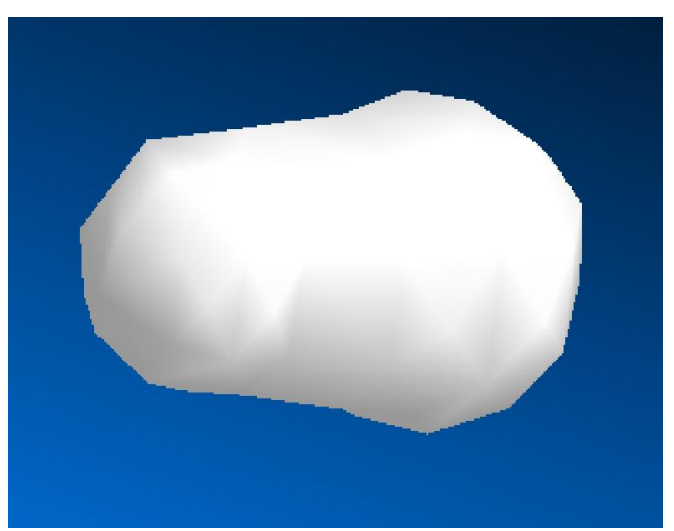

(d) 


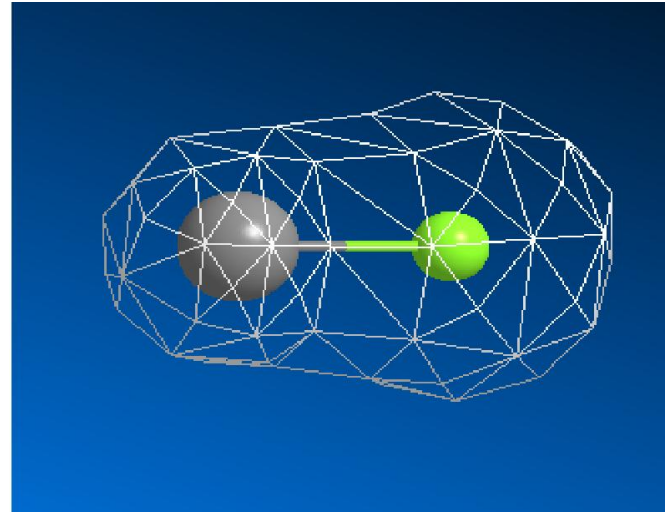

(e)

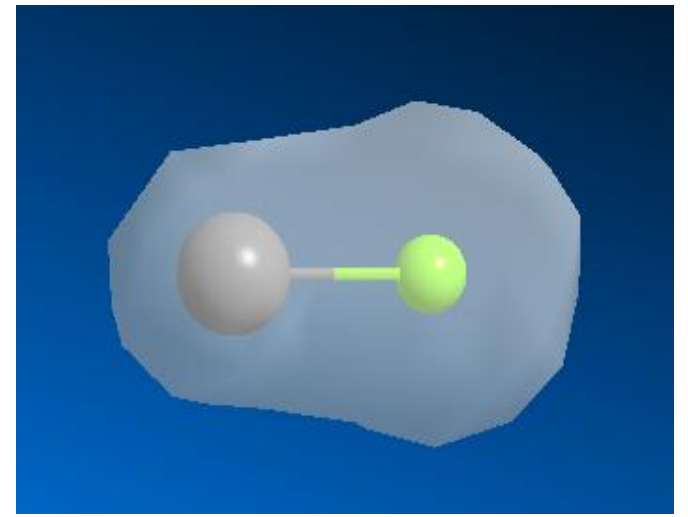

(f)

Gambar. 5 Analisis 3D Surface $\mathrm{NaCl}$ (a) Solvent Accessible $\mathrm{NaCl}$ Display Mode Solid (b) Solvent Accesible $\mathrm{NaCl}$ Display Mode Wire Mesh (c) Solvent Accessible $\mathrm{NaCl}$ Display Mode Translucent, (d) Collony molekular NaCl Display Mode Solid (e) Collony molekular $\mathrm{NaCl}$ Display Mode Wire Mesh (f) Collony molekular $\mathrm{NaCl}$ Display Mode Translucent. (Chemoffice 3D Version 15, Perkinelmer Informatic. Inc, 2015)

\section{Optimasi molekul NaCl dilakukan dengan Merk Molekular Force Field (MMFF94)}

Optimasi molekul $\mathrm{NaCl}$ dilakukan dengan menggunakan aplikasi ChemDraw3D. Berdasarkan hasil optimasi MMFF94 terhadap molekul $\mathrm{NaCl}$ didapatkan Energi Minimization sebesar $0.00073874 \mathrm{kcal} / \mathrm{mol}$, dan Molecular Dynamics dengan pergerakan sebanyak 30 kali menghasilkan energi rata-rata yang dibutuhkan sebanyak 101,4 kcal/mol.

Berdasarkan data yang telah didapatkan, energi sterik yang dibutuhkan antar atom yang berada didalam molekul ${ }^{[251-254]} \mathrm{NaCl}$ sangat kecil. Energi sterik adalah energi yang dilepaskan akibat terjadinya tumpang tindih awan elektron yang akan berpengaruh pada bentuk molekulnya. Pada molekul $\mathrm{NaCl}$,natrium dan klorin memiliki jarak yang cukup jauh, sehngga efek sterik yang terjadi kecil. Energi pergerakan atom-atom ${ }^{[239-242]}$ dalam molekul dalam jangka waktu tertentu. Interaksi yang terjadi sebanyak 30x menunjukan nilai yang hampir sama, dengan energi rata rata yang cukup besar. Hal ini dikarenakan ikatan ionik yang terbentuk pada molekul $\mathrm{NaCl}$, atom $\mathrm{Na}$ dan atom $\mathrm{Cl}$ berinteraksi kuat didalam molekulnya.

\section{Jari-Jari Atom Penyusun Senyawa $\mathrm{NaCl}$}

Berdasarkan hasil komputasi, didapatkan data jari jari atom pada keadaan bebas, jari jari atom pada molekul dan jari jari molekul. Pada atom klorin, jari jarinya yaitu 1.688, untuk anionnya jari jarinya sebesar 1.912. Sedangkan natrium memiliki jari jari sebesar 1.287. Jika dibandingkan antara jari jari ion dengan jari jari atom sebenarnya, jari jari atom yang membentuk ion ${ }^{[243]}$ positif ${ }^{(62-66)}$ akan lebih kecil dari semula. Sedangkan jari-jari atom yang membentuk ion negatif ${ }^{62}$; 67-70) akan lebih besar dari semula. Hal ini disebabkan karena adanya serahterima elektron. Didalam molekul, jari jsri atom lebih kecil dibandingkan dengan jari jari saat jadi unsur bebas. Hal ini disebabkan karena ikatan yang terbentuk pada atom. 


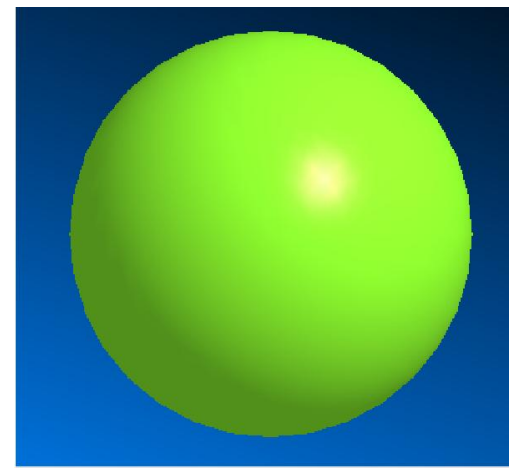

(a)

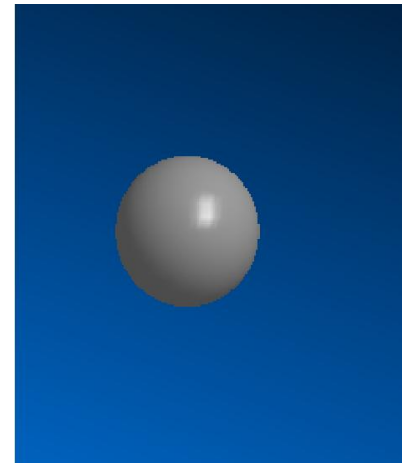

(b)

Gambar 4. (a) Analisis atom $\mathrm{Cl}$ menggunakan ChemDraw 3D (b) Analisis atom $\mathrm{Na}$ menggunakan ChemDraw 3D (Chemoffice 3D Version 15, Perkinelmer Informatic. Inc, 2015)

\section{Gerak Molekul}

Ada 3 pergerakan ion dalam larutan yaitu difusi, migrasi, dan koneksi.

a. Migrasi adalah pergerakan ion akibat pengaruh potensial dalam larutan b. Difusi ${ }^{(170-173)}$ adalah pergerakan ion akibat pengaruh konsentrasi larutan. c. Konveksi adalah pergerakan ion akibat pengaruh termal pada larutan.

Ion yang tersolvasi, dikelilingi oleh ion hidrogen yang tersolvasi ${ }^{[255-260]}$ oleh air dengan bentuk $\mathrm{H}_{3} \mathrm{O}^{+}$. Jika $\mathrm{NaCl}$ dilarutkan didalam air, maka akan terjadi pergerakan ion-ion secara difusi ${ }^{[244-250]}$. Artinya, ion $\mathrm{Na}^{+}$dan $\mathrm{Cl}^{-}$ bergerak dalam larutan akibat pengaruh konsentrasi larutan. Semakin encer larutan, semakin mudah ion bergerak dalam air.

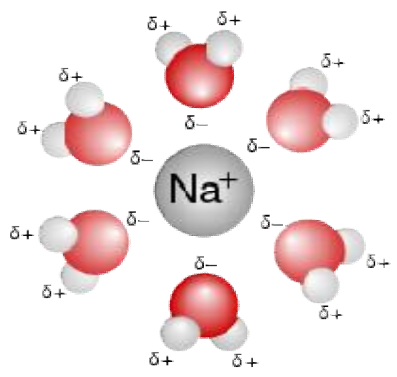

Gambar.7 Solvasi ion natrium dalam air

Sumber : http://id.m.wikipedia.org/wiki/larutan

Ion-ion ${ }^{(174)}$ yang berasal dari senyawa $\mathrm{NaCl}$ akan terion dan bergerak didalam air sehingga dapat menghantarkan listrik. $\mathrm{NaCl}$ terion sempurna dalam air $^{[261-265]}$. Ada beberapa parameter yang menyebabkan ion dari $\mathrm{NaCl}$ bergerak dan mengantarkan arus listrik.

\section{a. Konduktivitas}

Konduktivitas merupakan gerakan ion yang terjadi akibat pengaruh medan listrik $^{(177)}$. Hal ini menyebabkan larutan dapat mengantarkan listrik. 
Kemampuan suatu larutan dalam mengantarkan listrik disebut dengan konduktivitas listrik. Arus listrik dihantarkan oleh ion ion yang terkandung didalam larutan sehingga konduktivitas ${ }^{(178-181)}$ listrik hanya memperhitungkan banyaknya ion pada larutan.

Ada beberapa faktor yang mempengaruhi kecepatan ion dalam bergerak sehingga menghasilkan listrik ${ }^{(182-185)}$. Diantaranya sebagai berikut

a. Konsentrasi ion, pada larutan encer, ion lebih mudah bergerak sehingga daya hantarnya semakin besar.

b. Adanya hidrasi, pada pelarutan senyawa $\mathrm{NaCl}$, ion-ion yang tersusun rapat, akan terikat oleh molekul-molekul air. Molekul-molekul air tersebut akan menyusup disela-sela butir ion tersebut dan akhirnya natrium dan klorin akan terlepas satu sama lain dalam bentuk ion dan bergerak bebas dalam larutan.

c. Gaya tarik antar ion,semakin besar gaya tarik, semakin lambat gerakan ion.

d. Temperatur,semakin tinggi temperatur ${ }^{[227-231]}$,semakin cepat gerakan ion.

e. Viskositas, semakin besar viskositas larutan, semakin lambat gerakan ion dalam larutan.

Tabel 2. Konduktivitas $\mathrm{NaCl}$ berdasarkan variasi konsentrasi larutan

\begin{tabular}{ccc}
\hline Variabel & Konsentrasi NaCl & Konduktivitas Ion \\
\hline $\mathrm{X}_{1}$ & $2 \mathrm{M}$ & $46,8 \mathrm{mho} / \mathrm{cm}$ \\
$\mathrm{X}_{2}$ & $1 \mathrm{M}$ & $27,61 \mathrm{mho} / \mathrm{cm}$ \\
$\mathrm{X}_{3}$ & $0,1 \mathrm{M}$ & $3,61 \mathrm{mho} / \mathrm{cm}$ \\
$\mathrm{X}_{4}$ & $0.01 \mathrm{M}$ & $0,372 \mathrm{mho} / \mathrm{cm}$ \\
$\mathrm{X}_{5}$ & $0,001 \mathrm{M}$ & $0,0465 \mathrm{ohm} / \mathrm{cm}$ \\
\hline
\end{tabular}

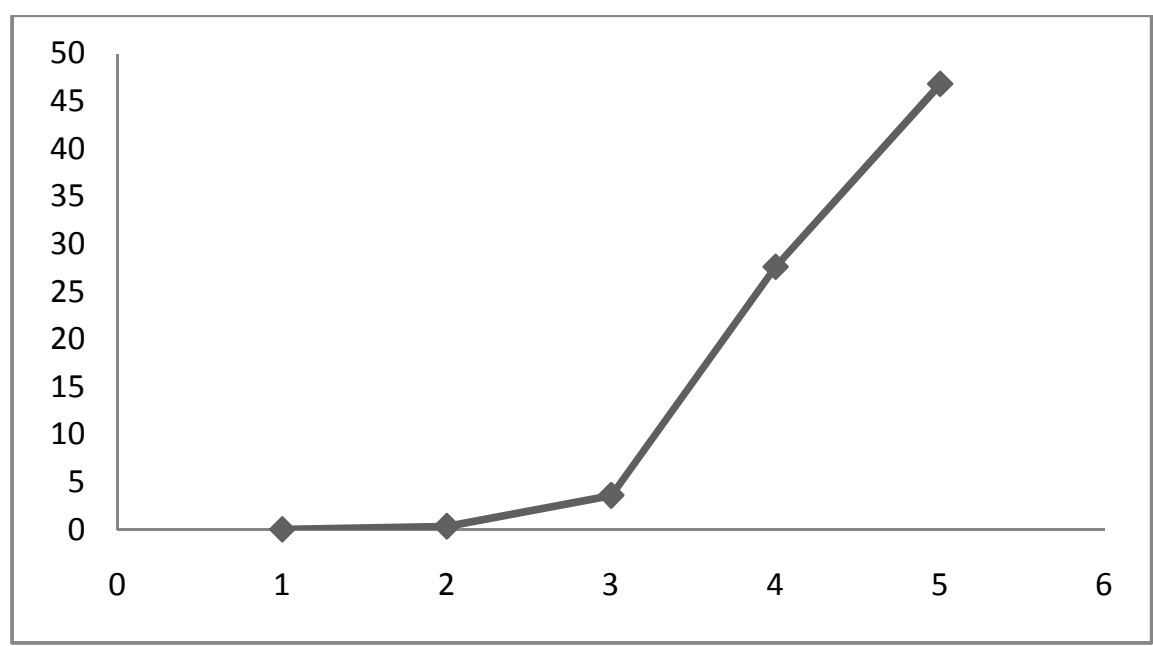

Grafik 1 . Pengaruh Konsentrasi Terhadap Konduktivitas ${ }^{(187-190)}$

Berdasarkan grafik yang didapatkan, diketahui bahwa semakin besar konsentrasi, maka konduktivitas larutan juga semakin besar.

Konduktivitas dapat dihitung dengan menggunakan rumus,

$$
K=\frac{1}{R} \times \frac{A}{L}\left(\Omega^{-1} c m^{-1}\right)
$$


Dimana $\rho$ adalah massa jenis ; 1 adalah jarak elektroda ${ }^{(191)}$; A adalah luas permukaan lempengan.

Konduktivitas untuk ion terisolasi adalah gaya yang disebabkan oleh medan listrik. Konduktivitas ini dapat dihitung menggunakan rumus,

$$
\mathrm{F}=\mathrm{Ze} \mathrm{xE}
$$

Dimana Ze adalah muatan masing-masing ion; dan E adalah medan listrik.

Konduktivitas untuk ion terisolasi ini diimbangi dengan gaya viskos (kekentalan) yang dirumuskan oleh persamaan stokes,

$$
\mathrm{F}=6 \pi \eta r v
$$

Dimana : $\eta$ adalah viskositas;r adalah jari jari;dan v adalah kecepatan.

Jika diketahui $\rho=2,16 \mathrm{~g} / \mathrm{cm}^{3}, l \mathrm{H} 2 \mathrm{O}=5 \times 10^{-8} \mathrm{mho} / \mathrm{cm}$ pada $25^{\circ} \mathrm{C}$ dan luas permukaan air $25 \mathrm{~cm}^{2}$. Tentukan konduktivitas dari ion $\mathrm{NaCl}$ !

$$
\begin{array}{ll}
\mathrm{R}=\rho \times \frac{l}{A} & \mathrm{~K}=\frac{1}{R \times A} \\
R=\frac{2,16 \mathrm{~g}}{\mathrm{~cm}^{\wedge} 3} \times \frac{5 \times 10^{-8} \mathrm{mho} / \mathrm{cm}}{25 \mathrm{~cm}^{\wedge}} & \mathrm{K}=\frac{1}{0,432 \times 10^{-8} \mathrm{mho} \mathrm{g} \mathrm{cm}^{-2} \times 25 \mathrm{~cm}^{2}} \\
\mathrm{R}=0,432 \times 10^{-8} \mathrm{mho} \mathrm{g} \mathrm{cm}^{-2} & \mathrm{~K}=0,0925 \times 10^{-8} \mathrm{mho} / \mathrm{cm}
\end{array}
$$

\section{b. Mobilitas ion}

Mobilitas $^{(195-202)}$ ion $^{(203-205)}$ adalah kecepatan ion pada beda potensial antara kedua elektroda. Mobilitas ion ${ }^{(192-194)}$ adalah perbandingan antara laju dan kuat medan .

$$
\mu=\frac{v}{E}
$$

Mobilitas ion juga dapat dihitung dengan menggunakan pengukurn yang sebenarnya antara jarak ${ }^{(206-215)}$ yang ditempuh setiap ion dengan waktu yang diperlukannya untuk menempuh jarak.

$$
\mu=\frac{x}{\Delta t}
$$

Jika di abaikan efek penghambat lain pada konduktor, maka laju ${ }^{(216-220)}$ maksimum adalah

$$
\mathrm{v}=\frac{\mathrm{Ze} \cdot \mathrm{E}}{6 \pi \eta \mathrm{rv}}=\mu . \mathrm{E}
$$

Dimana $\mu$ adalah mobilitas ion (perbandingan laju dan kuat medan)

Tabel 3. Nilai Mobilitas Ionik dari Ion Natrium dan Ion Klorin.

\begin{tabular}{cc}
\hline Ion & Mobilitas Ionik $\left(10^{-8} \mathrm{~m}^{2} \mathrm{~s}^{-1} \mathrm{~V}^{-1}\right)$ \\
\hline $\mathrm{Na}^{+}$ & 5,19 \\
$\mathrm{Cl}^{-}$ & 7,91 \\
\hline
\end{tabular}




\section{c. Konduktivitas Molar}

Konduktivitas molar adalah hantaran dari sejumlah volume larutan yang mengandung 1 mol elektrolit dan ditempatkan diantara 2 elektroda yang sejajar dan berjarak $1 \mathrm{~m}$.

Untuk menghitung konduktivitas molar $(\wedge \mathrm{m})$ digunakan rumus sebagai berikut :

$$
\wedge \mathrm{m}=\frac{k}{C}
$$

Dimana, $\mathrm{k}$ adalah konduktivitas $\left(\mathrm{Sm}^{-1}\right)$; dan $\mathrm{C}$ adalah konsentrasi (mol/L).

\section{d. Gaya Termodinamika Gradien Konsentrasi}

Dalam larutan dengan aktivasi partikel $\alpha$, maka potensial kimianya :

$$
\mu=\mu^{\theta}+\mathrm{RT} \ln \alpha
$$

Jika larutan tidak seragam, aktivitas itu bergantung pada posisinya dan kita dapat menuliskan :

$$
\mathrm{Te}=-\mathrm{RT}\left(\frac{\delta \ln a}{\delta x}\right)_{p . \mathrm{T}}
$$

Jika larutan itu ideal, $\alpha$ dapat digantikan dengan kosentrasi $c$, sehingga :

$$
\mathrm{Te}=\frac{-R T}{c}\left(\frac{\delta c}{\delta x}\right)_{p . T}
$$

\section{e. Hukum Pertama Fick Tentang Difusi}

Andaikan fluks pertikel yang berdifusi, merupakan gerakan sebagai reaksi terhadap gaya termodinamika yang timbul dari gradient konsentrasi ${ }^{[270-273]}$. Partikel ${ }^{[266-269]}$ akan mencapai kecepatan hanyut tetap $s$ jika gaya termodinamika $f$ sama dengan tahan kental.kecepatan hanyut ini sebanding dengan gaya termodinamika, dan kita tuliskan $s \propto$ f. Akan tetapi, fluks partikel $J$ sebanding dengan kecepatan hanyut, dan gaya termodinamika sebanding dengan gradient konsentrasid $c / d x$.

Rantai kesebandingan itu $(J \propto s, s \propto £$, dan $f \propto d c / d x$ menunjukkan bahwa:

$$
J \propto \frac{d c}{d x}
$$

\section{f. Hubungan Einstein}

Hukum Fick untuk fluks partikel dalam mol molekul ${ }^{(227)}$ per satuan luas per satuan waktu adalah:

$$
J=-D \frac{d c}{d x}
$$

Dengan $\mathrm{D}$ merupakan koefisien difusi dan $d c / d x$ merupakan kemiringan dari konsentrasi molar.

Fluks partikel berhubungan dengan kecepatan hanyut, dengan:

$$
J=s c
$$




\section{g. Hantaran Ion}

Hantaran molar ion pada pengenceran tidak berhingga adalah :

$$
\begin{aligned}
& v^{+} \lambda^{0+}=\left(t_{+}\right)^{0} \Lambda \\
& v^{-} \lambda^{0-}=\left(t_{-}\right)^{0} \Lambda
\end{aligned}
$$

Dimana $\left(t_{+}\right)^{0}=$ bilangan transport ion sampai pengenceran tak hingga; $\left(v^{+}\right)=$jumlah ion yang muatan positif.

\section{h. Viskositas}

Diketahui : Radius of $\mathrm{Na}^{+}=95 \mathrm{pm}$, Radius of $\mathrm{Cl}^{-}=181 \mathrm{pm}$, Radius Ratio $=$ $95 / 181=0.524, \rho$ air $=1,00\left(25^{\circ} \mathrm{C}, \mathrm{g} / \mathrm{cm}^{3}\right), \rho \mathrm{NaCl}=2,16\left(25^{\circ} \mathrm{C}, \mathrm{g} / \mathrm{cm}^{3}\right), \mathrm{v}$ $=1889 \mathrm{~m} / \mathrm{s}$

Ditanya : berapa besar viskositas dari $\mathrm{NaCl}$ ?

Jawaban :

$\eta=\frac{2 r^{2} g}{9 v}(\rho \mathrm{NaCl}-\rho$ air $)$

$\eta=\frac{2(0,524)^{2} 10 \mathrm{~kg} / \mathrm{m}^{3}}{9.1889 \mathrm{~m} / \mathrm{s}}\left(2,16 \times 10^{-3}-1,00 \times 10^{-3}\right) \mathrm{kg} / \mathrm{m}^{3}$

$\eta=\frac{5,49152 \mathrm{~kg} / \mathrm{m}^{3}}{17001 \mathrm{~m} / \mathrm{s}} 1,16 \times 10^{-3} \mathrm{~kg} / \mathrm{m}^{3}$

$\eta=0,374 \times 10^{-3} \mathrm{mPa} . \mathrm{s}$

\section{i. Daya Hanyut}

Diketahui $\mathrm{E}=2,085 \mathrm{eV} / \mathrm{cm}, \mu \mathrm{Na}^{+}=5,19 \times 10^{-8} \mathrm{~m}^{3} \mathrm{~s}^{-1} \mathrm{~V}^{-1}, \mu \mathrm{Cl}^{-}=7,91 \mathrm{X} 10^{-8} \mathrm{~m}^{3} \mathrm{~s}^{-}$ ${ }^{1} \mathrm{~V}^{-1}$, hitung daya hanyut ion $\mathrm{Na}^{+}$dan $\mathrm{Cl}^{-}$!

$v=\mu \cdot E$

\section{Untuk $\mathrm{Na}^{+}$}

$v=5,19 \times 10^{-8} \cdot 2,085 \mathrm{~m} / \mathrm{s}$

$v=10,821 \times 10^{-8} \mathrm{~m} / \mathrm{s}$

\section{Untuk $\mathrm{Cl}^{-}$}

$v=7,91 \times 10^{-8} \cdot 2,085 \mathrm{~m} / \mathrm{s}$

$v=16,492 \times 10^{-8} \mathrm{~m} / \mathrm{s}$

\section{Kegunaan $\mathrm{NaCl}$}

Natrium klorida memiliki banyak kegunaan dalam kehidupan sehari-hari, diantaranya adalah didalam tubuh, natrium klorida dapat berperan sebagai mengatasi /mencegah hilangnya natrium akibat beberapa hal seperti dehidrasi, keringat berlebih,dan sebagainya. $\mathrm{NaCl}$ juga berperan dalam tubuh sebagai 
penyerap dan pengangkut nutrisi, menjaga tekanan darah, menjaga keseimbangan cairan, mengirimkan signal syaraf, kontraksi dan rileks otot-otot. Selain berperan dalam tubuh, $\mathrm{NaCl}$ dapat digunakan untuk makanan seperti bumbu makanan,pengawet alami, meningkatkan warna alami makanan, mengawetkan daging, dan mengasinkan makanan. Kemudian, $\mathrm{NaCl}$ dapat digunakan sebagai rumah tangga seperti pembersih panci dan wajan, mencegah cetakan, menghapus noda dari grease, mencegah pembentukan es pada jalan bersalju. Selain itu, $\mathrm{NaCl}$ digunakan sebagai bahan cairan infus.

\section{Kesimpulan}

Natrium Klorida merupakan senyawa dengan rumus molekul $\mathrm{NaCl}$. Natrium klorida paling banyak digunakan sebagai bumbu masakan dalam kehidupan sehari-hari. Natrium klorida dapat disintesisi dengan metode kristalisasi atau dengan metode hidroekstraksi. Atom-atom penyusun natrium klorida adalah atom $\mathrm{Na}$, dan atom $\mathrm{Cl}$. Untuk mengetahui bentuk molekul dan pergerakan molekul yang dipengaruhi beberapa variabel seperti suhu, menggunakan permodelan dengan software ChemOffice 15.0. Permodelan dilakukan pada aplikasi ChemDraw 3D sebagai analisa molekular dalam 3 dimensi dan aplikasi ChemDraw 2D sebagai analisa molekular dalam 2 dimensi. Analisis jari-jari natrium klorida pada Chemdraw 3D didapatkan sebesar 2,530A, dan jari jari atom natrium dan klor masing-masingnya sebesar 1.287A dan 1.688A. Setelah dilakukan optimasi MMFF94, didapatkan energi sterik sebesar $0.00073874 \mathrm{kcal} / \mathrm{mol}$ dan energi molekul bergerak dalam 30 interaksi atomnya adalah $101,4 \mathrm{kcal} / \mathrm{mol}$. Natrium Klorida memiliki konduktivitas yang tinggi tergantung dari beberapa faktor seperti konsentrasi ion dalam larutan, semakin besar konsentrasi, semakin besar konduktivitas pada suatu larutan. Ion natrium memiliki mobilitas ion sebesar $5,1910^{-8} \mathrm{~m}^{2} \mathrm{~s}^{-1} \mathrm{~V}^{-}$ ${ }^{1}$,sedangkan mobilitas ion klorin sebesar $7,9110^{-8} \mathrm{~m}^{2} \mathrm{~s}^{-1} \mathrm{~V}^{-1}$. Natrium klorida memiliki nilai termodinamika yaitu $\Delta \mathrm{Gf}^{\circ}-411.2, \mathrm{kj} / \mathrm{mol}, \Delta \mathrm{Hf}^{\circ}-384.1 \mathrm{~S}^{\circ} 72.1$ dan C 50.5 . 
Reference :

1. Baus M, Rull LF, Ryckaert J-P, NATO Advanced Study Institute on Observation Prediction and Simulation of Phase Transitions in Complex Fluids :. 1995.

Observation, prediction and simulation of phase transitions in complex fluids.

Dordrecht: Kluwer Academic Publishers. xvii, 664 s. pp.

2. Jo.C.Fine., Phase, Yo A, Josefine. 1989. Jo.C.Fine. Pladecompagniet. 1 grammofonplade pp.

3. Jo.C.Fine., Phase, Yo A, Josefine. 1989. Respekt. Pladecompagniet. 1 grammofonplade $\mathrm{pp}$.

4. NATO Advanced Study Institute on Phase Transitions in Soft Condensed Matter : 1989 : Geilo)., Riste T, Sherrington DC. 1989. Phase transitions in soft condensed matter : proceedings of a NATO Advanced Study Institute on Phase Transitions in Soft Condensed MAtter, held April 4-14, 1989, in Geilo, Norway. New York: Plenum Press : publ. in cooperation with NATO Scientific Affairs Division. ix, 391 s. pp.

5. Starks CM, Liotta C. 1978. Phase transfer catalysis : principles and techniques. New York: Academic Press. ix, 365 s. pp.

6. Jia P, Tan H, Liu K, Gao W. 2018. Synthesis and Photocatalytic Performance of $\mathrm{ZnO} /$ Bone Char Composite. Materials 11

7. Hong Y, Ying T. 2018. Isolation, molecular characterization and antioxidant activity of a water-soluble polysaccharide extracted from the fruiting body of Termitornyces albuminosus (Berk.) Heim. International journal of biological macromolecules

8. Cochat P, Febvey O, Bacchetta J, Berard E, Cabrera N, Dubourg L. 2018. Towards adulthood with a solitary kidney. Pediatric nephrology

9. Febriani SS, Yolanda T, Arianti VA, Zainul R. 2018. A Review Solid Stated: Principles and Methode.

10. Nisa MU, Anjum S. 2018. Elective Induction versus Expectant Management of Mild Pre-Eclampsia at Term. Journal of the College of Physicians and Surgeons-Pakistan : JCPSP 28:677-80

11. Perreault L. 2018. Goals for Medical Treatment in Obesity and Prediabetes: Improving Outcomes for Both. Endocrine practice : official journal of the American College of Endocrinology and the American Association of Clinical Endocrinologists

12. Seidelmann SB, Feofanova E, Yu B, Franceschini N, Claggett B, et al. 2018. Genetic Variants in SGLT1, Glucose Tolerance, and Cardiometabolic Risk. Journal of the American College of Cardiology 72:1763-73

13. Cook DF, Jenkins SN, Abbott LK, D'Antuono MF, Telfer DV, et al. 2018. Amending Poultry Broiler Litter to Prevent the Development of Stable Fly, Stomoxys calcitrans (Diptera: Muscidae) and Other Nuisance Flies. Journal of economic entomology

14. Kokotsaki M, Mairhofer M, Schneeberger C, Marschalek J, Pietrowski D. 2018. Impact of vitrification on granulosa cell survival and gene expression. Cryobiology

15. Kvamme B, Selvag J, Saeidi N, Kuznetsova T. 2018. Methanol as a hydrate inhibitor and hydrate activator. Physical chemistry chemical physics : PCCP 20:21968-87

16. Costa RDS, Capuzzo CS, Ribeiro CDS, Verissimo-Silveira R, Siqueira-Silva DH, et al. 2018. Morphological evaluation of Prochilodus lineatus embryos after vitrification-thawing in high-osmolarity cryoprotectant solution. Reproduction in domestic animals $=$ Zuchthygiene

17. Dinata AA, Rosyadi AM, Hamid S, Zainul R. 2018. A Review CHEMICAL VAPOR DEPOSITION: PROCESS AND APPLICATION. 
18. Cabernard L, Roscher L, Lorenz C, Gerdts G, Primpke S. 2018. Comparison of Raman and Fourier Transform Infrared Spectroscopy for the Quantification of Microplastics in the Aquatic Environment. Environmental science \& technology

19. Temereva EN, Kuzmina TV. 2018. Spermatogenesis in the deep-sea brachiopod Pelagodiscus atlanticus and the phylogenetic significance of spermatozoon structure. Journal of morphology

20. Santhanam H, Farooqui A, Karthikeyan A. 2018. Bloom of the diatom, Biddulphia sp. and ecology of Pulicat lagoon, Southeast India in the aftermath of the 2015 north east monsoonal rainfall. Environmental monitoring and assessment 190:636

21. Ruhl IA, Grasby SE, Haupt ES, Dunfield PF. 2018. Analysis of microbial communities in natural halite springs reveals a domain-dependent relationship of species diversity to osmotic stress. Environmental microbiology reports

22. Plominsky AM, Henriquez-Castillo C, Delherbe N, Podell S, Ramirez-Flandes S, et al. 2018. Distinctive Archaeal Composition of an Artisanal Crystallizer Pond and Functional Insights Into Salt-Saturated Hypersaline Environment Adaptation. Frontiers in microbiology 9:1800

23. Khademi F, Derakhshan M, Yousefi-Avarvand A, Najafi A, Tafaghodi M. 2018. A novel antigen of Mycobacterium tuberculosis and MPLA adjuvant coentrapped into PLGA:DDA hybrid nanoparticles stimulates mucosal and systemic immunity. Microbial pathogenesis

24. $\mathrm{Hu}$ Y, Bu L, Wang X, Zhou L, Lu G. 2018. Field-effect Charge Transport in Doped Polymer Semiconductor-Insulator Alternating Bulk Junctions with Ultrathin Transport Layers. ACS applied materials \& interfaces

25. Ang BTW, Yap CH, Lee WSV, Xue JM. 2018. Bioinspired Dual-Tier Coalescence for Water Collection Efficiency Enhancement. Langmuir : the ACS journal of surfaces and colloids

26. Ma J, Bei Q, Wang X, Lan P, Liu G, et al. 2018. Impacts of Mo application on biological nitrogen fixation and diazotrophic communities in a flooded rice-soil system. The Science of the total environment 649:686-94

27. Tang XL, Suo H, Zheng RC, Zheng YG. 2018. An efficient colorimetric highthroughput screening method for synthetic activity of tyrosine phenol-lyase. Analytical biochemistry

28. Ding W, Liu Y, Wang D. 2018. Computational comparative mechanistic study of $\mathrm{C}-\mathrm{E}(\mathrm{E}=\mathrm{C}, \mathrm{N}, \mathrm{O}, \mathrm{S})$ couplings via $\mathrm{CO} 2$ activation mediated by uranium(III) complexes. Chemistry

29. Park J, Hinckley AC, Huang Z, Feng D, Yakovenko A, et al. 2018. Synthetic Routes for a 2D Semiconductive Copper Hexahydroxybenzene Metal-Organic Framework. Journal of the American Chemical Society

30. Frisco L, Miraglia JE, Gravielle MS. 2018. Spot-beam effect in grazing atomsurface collisions: From quantum to classical. Journal of physics. Condensed matter : an Institute of Physics journal

31. Abal P, Louzao MC, Suzuki T, Watanabe R, Vilarino N, et al. 2018. Toxic Action Reevaluation of Okadaic Acid, Dinophysistoxin-1 and Dinophysistoxin-2: Toxicity Equivalency Factors Based on the Oral Toxicity Study. Cellular physiology and biochemistry : international journal of experimental cellular physiology, biochemistry, and pharmacology 49:743-57

32. Goralsky LP, Dunaievska OF, Kolesnik NL, Stechenko LA, Grynevych NE, et al. 2018. [Ultramicroscopic features of cells and vessels of the spleen (experimental study)]. Wiadomosci lekarskie 71:1019-25

33. Tkachenko IM, Brailko NN, Kovalenko VV, Nazarenko ZJ, Sheshukova OV. 2018. [Morphological study of enamel and dentin teeth with carious process and non-carious lesions]. Wiadomosci lekarskie 71:1002-5 
34. Gomes FO, Maia LB, Cordas C, Moura I, Delerue-Matos C, et al. 2018. Electroanalytical characterization of the direct Marinobacter hydrocarbonoclasticus nitric oxide reductase-catalysed nitric oxide and dioxygen reduction. Bioelectrochemistry 125:8-14

35. Yuan M, Wang M, Lu P, Sun Y, Dipazir S, et al. 2018. Tuning carbon nanotubegrafted core-shell-structured cobalt selenide@carbon hybrids for efficient oxygen evolution reaction. Journal of colloid and interface science 533:503-12

36. Fatimah P, Jumalia R, Novianti ER, Zainul R. 2018. A REVIEW Teknik Blended: Prinsip dan Dasar-Dasar.

37. Shi Q, Jin X, Fan R, Xing M, Guo J, et al. 2018. Cadmium-mediated miR-30aGRP78 leads to JNK-dependent autophagy in chicken kidney. Chemosphere 215:710-5

38. Parveen S, Velmurugan G, Sinn E, Venuvanalingam P, Govindarajan S. 2018. Water-soluble Cobalt(II) \& Cobalt(III) complexes supported by new triazine Schiff base ligands: Synthesis, structure and biological evaluation. Journal of photochemistry and photobiology. B, Biology 189:152-64

39. Patra P, Ghosh M, Banerjee R, Chakrabarti J. 2018. Quantum chemical studies on anion specificity of C(alpha)NN motif in functional proteins. Journal of computer-aided molecular design 32:929-36

40. Shaharom S, Latif MT, Khan MF, Yusof SNM, Sulong NA, et al. 2018. Surfactants in the sea surface microlayer, subsurface water and fine marine aerosols in different background coastal areas. Environmental science and pollution research international 25:27074-89

41. Nieva NE, Borgnino L, Garcia MG. 2018. Long term metal release and acid generation in abandoned mine wastes containing metal-sulphides. Environmental pollution 242:264-76

42. Koshani R, van de Ven TGM, Madadlou A. 2018. Characterization of Carboxylated Cellulose Nanocrytals Isolated through Catalyst-Assisted $\mathrm{H} 2 \mathrm{O} 2$ Oxidation in a One-Step Procedure. Journal of agricultural and food chemistry 66:7692-700

43. Gan YY, Zhou SL, Dai X, Wu H, Xiong ZY, et al. 2018. Effect of iron salt type and dosing mode on Fenton-based pretreatment of rice straw for enzymatic hydrolysis. Bioresource technology 265:394-8

44. Melnik EV, Petukhov AE, Kozin SV, Pomerantseva TY, Ramenskaya GV. 2018. Validated HPLC-MS/MS method for quantification of ethylmethylhydroxypyridine succinate in rat brain and its application to a pharmacokinetic study. Journal of chromatography. B, Analytical technologies in the biomedical and life sciences 1096:180-6

45. Chen K, Yang L, Wu Z, Chen C, Jiang J, Zhang G. 2018. A computational study on the tunability of woven covalent organic frameworks for photocatalysis.

Physical chemistry chemical physics : $P C C P$

46. Hou J, Xie W, Hong D, Zhang W, Li F, et al. 2019. Simultaneous determination of ten neonicotinoid insecticides and two metabolites in honey and Royal-jelly by solid-phase extraction and liquid chromatography-tandem mass spectrometry. Food chemistry 270:204-13

47. Zhao C, Wang Z, Wang C, Li X, Wang CC. 2018. Photocatalytic degradation of DOM in urban stormwater runoff with $\mathrm{TiO} 2$ nanoparticles under UV light irradiation: EEM-PARAFAC analysis and influence of co-existing inorganic ions. Environmental pollution 243:177-88

48. Liu Y, Li Q, Su G, Wei D, Zheng M, et al. 2018. Photochemical conversion of toluene in simulated atmospheric matrix and characterization of large molecular weight products by +APPI FT-ICR MS. The Science of the total environment 649:111-9 
49. Banerjee P, Pandey P, Bandyopadhyay B. 2018. Stereo-preference of camphor for H-bonding with phenol, methanol and chloroform: A combined matrix isolation IR spectroscopic and quantum chemical investigation. Spectrochimica acta. Part A, Molecular and biomolecular spectroscopy 209:186-95

50. Calegari Andrade MF, Ko HY, Car R, Selloni A. 2018. Structure, Polarization, and Sum Frequency Generation Spectrum of Interfacial Water on Anatase TiO2. The journal of physical chemistry letters

51. Ge X, Li J, Luo R, Zhang C, Luo J. 2018. Macroscale Superlubricity Enabled by Synergy Effect of Graphene-oxide Nanoflakes and Ethanediol. ACS applied materials \& interfaces

52. Dereka B, Helbing J, Vauthey E. 2018. Transient Glass Formation around a Quadrupolar Photoexcited Dye in a Strongly H-Bonding Liquid Observed by Transient 2D-IR Spectroscopy. Angewandte Chemie

53. Song Y, Wightman E, Tian Y, Jack K, Li X, et al. 2018. Corrosion of reinforcing steel in concrete sewers. The Science of the total environment 649:739-48

54. Cherrier MV, Amara P, Talbi B, Salmain M, Fontecilla-Camps JC. 2018. Crystallographic evidence for unexpected selective tyrosine hydroxylations in an aerated achiral Ru-papain conjugate. Metallomics : integrated biometal science

55. Burger C, Atia-Tul-Noor A, Schnappinger T, Xu H, Rosenberger P, et al. 2018. Time-resolved nuclear dynamics in bound and dissociating acetylene. Structural dynamics 5:044302

56. Das L, Adhikari S. 2018. Direct Observation of Solvated Electrons in Deep Eutectic Solvents: Efficient Capture of Pre-Solvated Electron by DNA Base. The journal of physical chemistry. $B$

57. Jiang Y, Jianxiong Zeng R. 2018. Expanding the product spectrum of value added chemicals in microbial electrosynthesis through integrated process designA review. Bioresource technology

58. Haskopoulos A, Maroulis G, Bancewicz T. 2018. Interaction-induced electric (hyper)polarizability in the dihydrogen-neon pair: basis set and electron correlation effects. Journal of molecular modeling 24:265

59. Battiato M, Minar J, Wang W, Ndiaye W, Richter MC, et al. 2018. Distinctive Picosecond Spin Polarization Dynamics in Bulk Half Metals. Physical review letters 121:077205

60. Volkova LM, Marinin DV. 2018. Antiferromagnetic spin-frustrated layers of corner-sharing $\mathrm{Cu}<\mathrm{sub}>4</$ sub $>$ tetrahedra on the kagome lattice in volcanic minerals

$\mathrm{Cu}<$ sub $>5</$ sub $>0<$ sub $>2</$ sub $>(\mathrm{VO}<$ sub $>4</$ sub $>)<$ sub $>2</$ sub $>(\mathrm{CuCl})$, $\mathrm{NaCu}<$ sub $>5</$ sub $>\mathrm{O}<$ sub $>2</$ sub $>(\mathrm{SeO}<$ sub $>3</$ sub $>)<$ sub $>2</$ sub $>\mathrm{Cl}<$ sub $>3$ $</$ sub $>$, and

$\mathrm{K}<$ sub $>2</$ sub $>\mathrm{Cu}<$ sub $>5</$ sub $>\mathrm{Cl}<$ sub $>8</$ sub $>(\mathrm{OH})<$ sub $>4</$ sub $>.2 \mathrm{H}<$ sub $>2$ $</$ sub $>$ O. Journal of physics. Condensed matter : an Institute of Physics journal

61. Bian Y, Kang L, Ren Q, Zheng Y, Engel-Herbert R, et al. 2018. Hybrid vanadate waveguiding configurations for extreme optical confinement and efficient polarization management in the near-infrared. Nanoscale

62. Li F, Fang X, Zhou Z, Liao X, Zou J, et al. 2018. Adsorption of perfluorinated acids onto soils: Kinetics, isotherms, and influences of soil properties. The Science of the total environment 649:504-14

63. Karasawa T, Oriez R, Kumagai N, Shibasaki M. 2018. anti-Selective Catalytic Asymmetric Nitroaldol Reaction of alpha-Keto Esters; Intriguing Solvent Effect, Flow Reaction, and Synthesis of APIs. Journal of the American Chemical Society

64. Levason W, Monzittu FM, Reid G, Zhang W. 2018. Neutral and cationic tungsten(vi) fluoride complexes with tertiary phosphine and arsine coordination. Chemical communications 
65. Xu J, Wei Y, Yang W, Yang L, Yi Z. 2018. The mechanism and conformational changes of polybrominated diphenyl ethers to TTR by fluorescence spectroscopy, molecular simulation, and quantum chemistry. The Analyst

66. Tega Y, Yamazaki Y, Akanuma SI, Kubo Y, Hosoya KI. 2018. Impact of Nicotine Transport across the Blood-Brain Barrier: Carrier-Mediated Transport of Nicotine and Interaction with Central Nervous System Drugs. Biological \& pharmaceutical bulletin 41:1330-6

67. Pike A, Flanagan NJ, Storer RI, Swain NA, Tseng E. 2018. The role of organic anion-transporting polypeptides and formulation in the clearance and distribution of a novel Nav 1.7 channel blocker. Biopharmaceutics \& drug disposition

68. Ikeda R, Ichikawa T, Tsukiji YK, Kawamura K, Kikuchi A, et al. 2018. [Identification of Heparin-binding Proteins on the Cell Surface of Cryptococcus neoformans]. Medical mycology journal 59:E47-E52

69. Nakamura Y, Nakanishi T, Tamai I. 2018. Membrane Transporters Contributing to PGE2 Distribution in Central Nervous System. Biological \& pharmaceutical bulletin 41:1337-47

70. Yoshikado T, Toshimoto K, Maeda K, Kusuhara H, Kimoto E, et al. 2018. PBPK modeling of coproporphyrin I as an endogenous biomarker for drug interactions involving inhibition of hepatic OATP1B1 and OATP1B3. CPT: pharmacometrics \& systems pharmacology

71. Rechberger MV, Kloss S, Wang SL, Lehmann J, Rennhofer H, et al. 2018. Enhanced $\mathrm{Cu}$ and $\mathrm{Cd}$ sorption after soil aging of woodchip-derived biochar: What were the driving factors? Chemosphere 216:463-71

72. Kumar V, Sharma A, Kaur P, Singh Sidhu GP, Bali AS, et al. 2018. Pollution assessment of heavy metals in soils of India and ecological risk assessment: A state-of-the-art. Chemosphere 216:449-62

73. Yue K, Yang W, Tan B, Peng Y, Huang C, et al. 2018. Immobilization of heavy metals during aquatic and terrestrial litter decomposition in an alpine forest. Chemosphere 216:419-27

74. Backman R. 1989. Sodium and sulfur chemistry in combustion gases. Disputats, Åbo akademi. Åbo akademi,, Åbo. 1 bd. (flere pag.). pp.

75. Eriksson S. 1982. Cerebrospinal fluid salinity and body fluid homeostasis : studies on putative juxtacerebroventricular sodium sensitivity in the goat. Thesis. s.n. ,, Stockh. 35 s. pp.

76. Fitzsimons JT, Physiological Society. 1979. The physiology of thirst and sodium appetite. Cambridge: Cambridge University Press. xv, 572 s. pp.

77. Hansen HS. 1993. Blood pressure, physical fitness, cardiac structure and sodium-potassium pump activity in a population of children : the impact of primary intervention with physical training : the Odense schoolchild study. Disputats, Odense Universitet. Eget forlag,, Odense. 65 sider pp.

78. Kornerup HJ. 1980. Pathophysiological and clinical aspects concerning the renin-angiotensin system and the body sodium content in renal and postrenaltransplant hypertension in humans : a survey. Disputats, Århus. Århus Universitet,, Århus. 58 s. pp.

79. Meyland I, Statens Levnedsmiddelinstitut. 1983. Magnesium-, natrium- og kaliumindholdet $i$ danske levnedsmidler $=$ The content of magnesium, sodium and potassium in Danish foods. Søborg: Statens Levnedsmiddelinstitut, Centrallaboratoriets afdeling A: næringsstoffer og tilsætningsstoffer. 70 sider pp.

80. Novak L. 1979. Sodium salt scaling in connection with evaporation of black liquors and pure model solutions. Akad avh. s.n. „, Göteborg. 161 s. pp.

81. Papper S. 1982. Sodium : its biologic significance. Boca Raton, Fla.: CRC. 293 s. pp. 
82. Tudorovskaya M, Minns RS, Kirrander A. 2018. Effects of probe energy and competing pathways on time-resolved photoelectron spectroscopy: the ringopening of 1,3-cyclohexadiene. Physical chemistry chemical physics : PCCP 20:17714-26

83. Michoulier E, Ben Amor N, Rapacioli M, Noble JA, Mascetti J, et al. 2018. Theoretical determination of adsorption and ionisation energies of polycyclic aromatic hydrocarbons on water ice. Physical chemistry chemical physics : PCCP 20:11941-53

84. Laskowski D, Andersson G, Humblot P, Sirard MA, Sjunnesson Y, et al. 2018. Lipid profile of bovine blastocysts exposed to insulin during in vitro oocyte maturation. Reproduction, fertility, and development

85. Habib S, Ahmad SA, Johari WLW, Shukor MYA, Alias SA, et al. 2018. Evaluation of conventional and response surface level optimisation of $\mathrm{n}$-dodecane (n-C12) mineralisation by psychrotolerant strains isolated from pristine soil at Southern Victoria Island, Antarctica. Microbial cell factories 17:44

86. Prieto-Pena J, Gomez F, Gonzalez-Castano DM, Flores-Arias MT, Arines J, et al. 2018. Radiation characterisation and dosimetric measurements of a femtosecond pulsed laser ablation system. Journal of radiological protection : official journal of the Society for Radiological Protection 38:716-30

87. Buch Salomonsen K. 2000. Potentiale og barrierer for biogasproduktion $i$ Danmark ved omfattende økologisk jordbrug med fokus på dyrkningsjordens kulstofforhold. Ph d -afhandling. Institut for Bygninger og Energi, Danmarks Tekniske Universitet, Lyngby. 83 s. pp.

88. Danmark. DANCED. 2000. Thailand-Danish country programme for environmental assistance 1998-2001. Copenhagen: DANCED : available from: ... Miljøbutikken. 49 sider. pp.

89. International Energy Agency. 1989. Electricity end-use efficiency. Paris: OECD. 200 s. pp.

90. OECD. International Energy Agency. 2000. Energy policies of IEA countries : Sweden 2000 review. Paris: Organisation for Economic Co-operation and Development. 142 s. pp.

91. OECD. Nuclear Energy Agency., Sverige. Statens strålskyddsinstitut., Swedish National Institute of Radiation Protection., National Institute of Radiation Protection. 1990. Emergency preparedness for nuclear-powered satellites : Stockholm, Sweden, 24-26 april 1989. Paris: OECD. 103 s. pp.

92. Ameixa J, Arthur-Baidoo E, Meissner R, Makurat S, Kozak W, et al. 2018. Lowenergy electron-induced decomposition of 5-trifluoromethanesulfonyl-uracil: A potential radiosensitizer. The Journal of chemical physics 149:164307

93. Kondyli A, Schrader W. 2018. High-resolution GC/MS studies of a light crude oil fraction. Journal of mass spectrometry : JMS

94. Chen W, Deng Y, Russell E, Wu Y, Abel R, Wang L. 2018. Accurate calculation of relative binding free energies between ligands with different net charges.

Journal of chemical theory and computation

95. Jacobs MI, Davis RD, Rapf RJ, Wilson KR. 2018. Studying Chemistry in Microcompartments by Separating Droplet Generation from Ionization. Journal of the American Society for Mass Spectrometry

96. Hassan H, Amiruddin MD, Weckwerth W, Ramli US. 2018. Deciphering key proteins of oil palm (Elaeis guineensis Jacq.) fruit mesocarp development by proteomics and chemometrics. Electrophoresis

97. Utecht M, Gaebel T, Klamroth T. 2018. Desorption induced by low energy charge carriers on $\mathrm{Si}(111)-7$ x 7: First principles molecular dynamics for benzene derivates. Journal of computational chemistry 
98. Beeksma B, Lehmann J. 2018. Excessive applicator radiation leakage for a common therapeutic kilovoltage system. The British journal of radiology:20180743

99. Sato TK, Asai M, Borschevsky A, Beerwerth R, Kaneya Y, et al. 2018. First Ionization Potentials of Fm, Md, No, and Lr: Verification of Filling-Up of $5 \mathrm{f}$ Electrons and Confirmation of the Actinide Series. Journal of the American Chemical Society

100. Foley CD, Joalland B, Alavi ST, Suits AG. 2018. Mixed transitions in the UV photodissociation of propargyl chloride revealed by slice imaging and multireference ab initio calculations. Physical chemistry chemical physics : $P C C P$

101. Liyanage OT, Brantley MR, Calixte EI, Solouki T, Shuford KL, Gallagher ES. 2018. Characterization of Electrospray Ionization (ESI) Parameters on In-ESI Hydrogen/Deuterium Exchange of Carbohydrate-Metal Ion Adducts. Journal of the American Society for Mass Spectrometry

102. Hsu YT, Lee TM. 2018. Abscisic acid-dependent nitric oxide pathway and abscisic acid-independent nitric oxide routes differently modulate $\mathrm{NaCl}$ stress induction of the gene expression of methionine sulfoxide reductase A and B in rice roots. Journal of plant physiology 231:374-82

103. Zoya A, Tewari RK, Mishra SK, Faisal SM, Ali S, et al. 2018. Sodium percarbonate as a novel intracoronal bleaching agent: assessment of the associated risk of cervical root resorption. International endodontic journal

104. de Paula Menezes R, Silva FF, Melo SGO, Alves PGV, Brito MO, et al. 2018. Characterization of Candida species isolated from the hands of the healthcare workers in the neonatal intensive care unit. Medical mycology

105. Severing AL, Rembe JD, Koester V, Stuermer EK. 2018. Safety and efficacy profiles of different commercial sodium hypochlorite/hypochlorous acid solutions ( $\mathrm{NaClO} / \mathrm{HClO})$ : antimicrobial efficacy, cytotoxic impact and physicochemical parameters in vitro. The Journal of antimicrobial chemotherapy

106. Reeve E, Naseri T, Martyn T, Bollars C, Thow AM. 2018. Developing a contextspecific nutrient profiling system for food policy in Samoa. Health promotion international

107. Zhou H, Zhang HJ, Guan L, Zhang YN, Li Y, Sun MJ. 2018. Mechanism and therapeutic effects of Saccharomyces boulardii on experimental colitis in mice. Molecular medicine reports

108. Pang J, Mendes RG, Bachmatiuk A, Zhao L, Ta HQ, et al. 2018. Applications of 2D MXenes in energy conversion and storage systems. Chemical Society reviews

109. Schaefer I, Prato V, Arcourt A, Taberner FJ, Lechner SG. 2018. [EXPRESS] Differential modulation of voltage-gated sodium channels by nerve growth factor in three major subsets of TrkA-expressing nociceptors. Molecular pain: 1744806918814640

110. Wang R, Du X, Wu Y, Zhai J, Xie X. 2018. Graphene Quantum Dots Integrated in Ionophore-based Fluorescent Nanosensors for $\mathrm{Na}(+)$ and $\mathrm{K}()$. ACS sensors

111. Hu C, Sun J, Zhang Y, Chen J, Lei Y, et al. 2018. Local Delivery and SustainedRelease of Nitric Oxide Donor Loaded in Mesoporous Silica Particles for Efficient Treatment of Primary Open-Angle Glaucoma. Advanced healthcare materials:e1801047

112. Schoppe P, Schonherr S, Jackson P, Wuerz R, Wisniewski W, et al. 2018. Overall Distribution of Rubidium in Highly Efficient $\mathrm{Cu}(\mathrm{In}, \mathrm{Ga}) \mathrm{Se} 2$ Solar Cells. ACS applied materials \& interfaces

113. Harel F, Finnerty V, Authier S, Pelletier-Galarneau M. 2018. Comparison of two dipyridamole infusion protocols for myocardial perfusion imaging in subjects with low likelihood of significant obstructive coronary artery disease. Journal of 
nuclear cardiology : official publication of the American Society of Nuclear Cardiology

114. Thiele T, Lin Y, Brown MO, Regal CA. 2018. Self-Calibrating Vector Atomic Magnetometry through Microwave Polarization Reconstruction. Physical review letters 121:153202

115. Mancebo G, Gil-Moreno A, Verges R, Martinez-Palones JM, Checa MA, et al. 2010. Out-of-protocol concurrent use of cisplatin and radiation therapy in locally advanced cervical cancer: feasibility and survival. European journal of gynaecological oncology 31:18-22

116. Wang G, Hwang JN, Rose C, Wallace F. 2018. Uncertainty Based Active Learning via Sparse Modeling for Image Classification. IEEE transactions on image processing : a publication of the IEEE Signal Processing Society

117. Fox D, Sheehan A, Homer CS. 2018. Birthplace in Australia: Antenatal preparation for the possibility of transfer from planned home birth. Midwifery $66: 134-40$

118. Johnson BB. 2018. Residential Location and Psychological Distance in Americans' Risk Views and Behavioral Intentions Regarding Zika Virus. Risk analysis : an official publication of the Society for Risk Analysis

119. Smith CCR, Flaxman SM, Scordato ESC, Kane NC, Hund AK, et al. 2018. Demographic inference in barn swallows using whole genome data shows signal for bottleneck and subspecies differentiation during the Holocene. Molecular ecology

120. Choo PJ, Tan JYT, Ong LT, Aw AT, Teo LW, et al. 2018. Role transition: A descriptive exploratory study of assistant nurse clinicians in Singapore. Journal of nursing management

121. Korsak D, Chmielowska C, Szuplewska M, Bartosik D. 2018. Prevalence of plasmid-borne benzalkonium chloride resistance cassette bcrABC and cadmium resistance cadA genes in nonpathogenic Listeria spp. isolated from food and food-processing environments. International journal of food microbiology 290:247-53

122. Liang J, Smith KD, Lu H, Seale TW, Gan RZ. 2018. Mechanical properties of the Papio anubis tympanic membrane: Change significantly from infancy to adulthood. Hearing research 370:143-54

123. Cardoso AR, Marques AC, Santos L, Carvalho AF, Costa FM, et al. 2018. Molecularly-imprinted chloramphenicol sensor with laser-induced graphene electrodes. Biosensors \& bioelectronics 124-125:167-75

124. Cai LM, Wang QS, Wen HH, Luo J, Wang S. 2018. Heavy metals in agricultural soils from a typical township in Guangdong Province, China: Occurrences and spatial distribution. Ecotoxicology and environmental safety 168:184-91

125. Hardcastle K, Bellis MA, Ford K, Hughes K, Garner J, Ramos Rodriguez G. 2018. Measuring the relationships between adverse childhood experiences and educational and employment success in England and Wales: findings from a retrospective study. Public health 165:106-16

126. Shi J, Deng Q, Li Y, Zheng MM, Chai Z, et al. 2018. A Rapid and Ultrasensitive Tetraphenylethylene-based Probe with Aggregation-Induced Emission for Direct Detection of alpha-Amylase in Human Body Fluids. Analytical chemistry

127. Peddi S, Pan X, MacKay JA. 2018. Intracellular Delivery of Rapamycin From FKBP Elastin-Like Polypeptides Is Consistent With Macropinocytosis. Frontiers in pharmacology 9:1184

128. Wollmer E, Neal G, Whitaker MJ, Margetson D, Klein S. 2018. Biorelevant in vitro assessment of dissolution and compatibility properties of a novel paediatric hydrocortisone drug product following exposure of the drug product to childappropriate administration fluids. European journal of pharmaceutics and 
biopharmaceutics : official journal of Arbeitsgemeinschaft fur Pharmazeutische Verfahrenstechnik e.V

129. Lu Q, Dun J, Chen JM, Liu S, Calvin Sun C. 2018. Improving solid-state properties of berberine chloride through forming a salt cocrystal with citric acid. International journal of pharmaceutics

130. Alayoubi A, Sabir Aqueel M, Cruz CN, Ashraf M, Zidan AS. 2018. Application of in vitro lipolysis for the development of oral self-emulsified delivery system of Nimodipine. International journal of pharmaceutics

131. Jeon C, Han J, Seo M. 2018. Control of Ion Transport in Sulfonated Mesoporous Polymer Membranes. ACS applied materials \& interfaces

132. Li M, Wang C, Chen J, Guo Z, Mou Z, Luo Y. 2018. Controlled iso-specific polymerization of 2-vinylpyridine catalyzed by arylamide-ligated rare-earth metal aminobenzyl complexes. Dalton transactions

133. Wei W, Mandin C, Blanchard O, Mercier F, Pelletier M, et al. 2019. Semivolatile organic compounds in French dwellings: An estimation of concentrations in the gas phase and particulate phase from settled dust. The Science of the total environment 650:2742-50

134. Zhang M, Wu J, Han J, Shu H, Liu K. 2018. Isolation of polysaccharides from Dendrobium officinale leaves and anti-inflammatory activity in LPS-stimulated THP-1 cells. Chemistry Central journal 12:109

135. Zhao J, Wang T, Xie J, Xiao Q, Du W, et al. 2019. Meat flavor generation from different composition patterns of initial Maillard stage intermediates formed in heated cysteine-xylose-glycine reaction systems. Food chemistry 274:79-88

136. Chaidir, z., Zainul, R., Nurakhbari, D., \& Salim, M. (2016, September 24). Optimization of Spirulina Platensis Culture for Antioxidant Production. https://doi.org/10.17605/OSF.IO/FD6E4

137. Matsumoto K, Takayanagi M, Suzuki Y, Koga N, Nagaoka M. 2018. Atomistic chemical computation of Olefin polymerization reaction catalyzed by (pyridylamido)hafnium(IV) complex: Application of Red Moon simulation. Journal of computational chemistry

138. Yan H, Chircov C, Zhong X, Winkeljann B, Dobryden I, et al. 2018. Reversible condensation of mucins into nanoparticles. Langmuir : the ACS journal of surfaces and colloids

139. Zhang T, Wang Q, Deng Y, Jiang R. 2018. Recovery of Phosphorus From Swine Manure by Ultrasound/H2O2 Digestion, Struvite Crystallization, and Ferric Oxide Hydrate/Biochar Adsorption. Frontiers in chemistry 6:464

140. Selim MB, Nobrega FS, Faco LL, Filippo Hagen SC, De Zoppa A, et al. 2018. Histological and Radiographic Evaluation of Equine Bone Structure after Implantation of Castor Oil Polymer. Veterinary and comparative orthopaedics and traumatology : V.C.O.T

141. Ganjaei KG, Soler ZM, Mappus ED, Worley ML, Rowan NR, et al. 2018. Radiologic changes in the aging nasal cavity. Rhinology

142. Oh JK, Im YJ, Park K, Paick JS. 2018. Effects of combined growth hormone and testosterone treatments in a rat model of micropenis. Endocrine connections

143. Saha S, Mishra MK, Reddy CM, Desiraju GR. 2018. From Molecules to Interactions to Crystal Engineering: Mechanical Properties of Organic Solids. Accounts of chemical research

144. Sierra-Almeida A, Cavieres LA, Bravo LA. 2018. Warmer Temperatures Affect the in situ Freezing Resistance of the Antarctic Vascular Plants. Frontiers in plant science 9:1456

145. Cai Q, Fauvart M, Wiederkehr RS, Jones B, Cools P, et al. 2019. Ultra-fast, sensitive and quantitative on-chip detection of group B streptococci in clinical samples. Talanta 192:220-5 
146. Proctor JE, Bailey M, Morrison I, Hakeem MA, Crowe IF. 2018. Observation of Liquid-Liquid Phase Transitions in Ethane at $300 \mathrm{~K}$. The journal of physical chemistry. $B$

147. Ashrafi B, Tootoonchi MH, Bardsley R, Molano RD, Ruiz P, et al. 2018. Stable perfluorocarbon emulsions for the delivery of halogenated ether anesthetics. Colloids and surfaces. B, Biointerfaces 172:797-805

148. Qiu X, Tan SP, Dejam M, Adidharma H. 2018. Novel isochoric measurement of the onset of vapor-liquid phase transition using differential scanning calorimetry. Physical chemistry chemical physics : PCCP

149. Kesharwani SS, Kaur S, Tummala H, Sangamwar AT. 2018. Multifunctional approaches utilizing polymeric micelles to circumvent multidrug resistant tumors. Colloids and surfaces. B, Biointerfaces 173:581-90

150. Fernandes C, Martins CAU, Fonseca A, Nunes R, Matos MJ, et al. 2018. PEGylated PLGA nanoparticles as a smart carrier to increase the cellular uptake of a coumarin-based monoamine oxidase $\mathrm{B}$ inhibitor. ACS applied materials \& interfaces

151. Vinarov Z, Katev V, Burdzhiev N, Tcholakova S, Denkov ND. 2018. Effect of surfactant-bile interactions on the solubility of hydrophobic drugs in biorelevant dissolution media. Molecular pharmaceutics

152. Zheng Y, Liu L, Xiao L, Zhang Q, Liu Y. 2018. Enhanced osteogenic activity of phosphorylated polyetheretherketone via surface-initiated grafting polymerization of vinylphosphonic acid. Colloids and surfaces. B, Biointerfaces 173:591-8

153. Coffin S, Dudley S, Taylor A, Wolf D, Wang J, et al. 2018. Comparisons of analytical chemistry and biological activities of extracts from North Pacific gyre plastics with UV-treated and untreated plastics using in vitro and in vivo models. Environment international 121:942-54

154. Kalantari M, Zhang J, Liu Y, Yu C. 2018. Dendritic mesoporous carbon nanoparticles for ultrahigh and fast adsorption of anthracene. Chemosphere 215:716-24

155. Crystal D. 1981. Directions in applied linguistics. London: Academic Press. 179 s. pp.

156. Crystal D. 1991. Rediscover grammar with David Crystal. Harlow: Longman. 223 s. pp.

157. Crystal D. 1998. The Cambridge biographical encyclopedia. Cambridge: Cambridge University Press. xi, 1179 s. pp.

158. Crystal D. 1998. Language play. London: Penguin Books. 248 s. pp.

159. Crystal D. 2000. Language death. Cambridge: Cambridge University Press. x, 198 s. pp.

160. Kebede G, Mitev PD, Broqvist P, Eriksson A, Hermansson K. 2018. Fifty shades of water: Benchmarking DFT functionals against experimental data for ionic crystalline hydrates. Journal of chemical theory and computation

161. Zhu Y, Han Z, Fu L, Liu C, Zhang D. 2018. Cleavage of the beta-O-4 bond in a lignin model compound using the acidic ionic liquid 1-H-3-methylimidazolium chloride as catalyst: a DFT mechanistic study. Journal of molecular modeling 24:322

162. Akhtar N, Jabeen I, Jalal N, Antilla J. 2018. Structure-Based Pharmacophore Models to Probe Anticancer Activity of Inhibitors of Protein Kinase B-beta (PKB beta). Chemical biology \& drug design

163. Gao S, Xu L, Zhang Y, Yu Q, Li J, et al. 2018. Salusin-alpha Inhibits Proliferation and Migration of Vascular Smooth Muscle Cell via Akt/mTOR Signaling. Cellular physiology and biochemistry : international journal of experimental cellular physiology, biochemistry, and pharmacology 50:1740-53 
164. Xia F, Chen Y, Jiang B, Du X, Peng Y, et al. 2018. Long Noncoding RNA HOXA-AS2 Promotes Papillary Thyroid Cancer Progression by Regulating miR520c-3p/S100A4 Pathway. Cellular physiology and biochemistry : international journal of experimental cellular physiology, biochemistry, and pharmacology 50:1659-72

165. Fang J, Zhang S, Xue X, Zhu X, Song S, et al. 2018. Quercetin and doxorubicin co-delivery using mesoporous silica nanoparticles enhance the efficacy of gastric carcinoma chemotherapy. International journal of nanomedicine 13:5113-26

166. Selladurai S, Thittai AK. 2018. Towards quantitative quasi-static ultrasound elastography using a reference layer for liver imaging application: A preliminary assessment. Ultrasonics 93:7-17

167. Wang L, Jia Y, Yang G, Mao G, Cheng Y, Cao Y. 2018. Primary hyperparathyroidism characterized by diffuse homogeneous metastatic pulmonary calcification: A case report. Medicine 97:e13107

168. Yu F, Huang Y, Wang Y, Yu Z, Li X, Dong J. 2018. Very late onset posttransplant diffuse large B cell lymphoma in a liver transplant recipient with hepatitis B: A case report. Medicine 97:e13063

169. Corby S, Francas L, Selim S, Sachs M, Blackman C, et al. 2018. Water oxidation and electron extraction kinetics in nanostructured tungsten trioxide photoanodes. Journal of the American Chemical Society

170. Liza YM, Yasin RC, Maidani SS, Zainul R. 2018. SOL GEL: PRINCIPLE AND TECHNIQUE (A REVIEW).

171. Zhao X, Jia Y, Liu ZH. 2018. GO-graphene ink-derived hierarchical 3Dgraphene architecture supported $\mathrm{Fe} 3 \mathrm{O} 4$ nanodots as high-performance electrodes for lithium/sodium storage and supercapacitors. Journal of colloid and interface science 536:463-73

172. Gitis M. 2018. On the interpretation of shear viscosity ultrasonic measurements. Ultrasonics 93:1-6

173. Stachowska-Pietka J, Poleszczuk J, Flessner MF, Lindholm B, Waniewski J. 2018. Alterations of peritoneal transport characteristics in dialysis patients with ultrafiltration failure: tissue and capillary components. Nephrology, dialysis, transplantation : official publication of the European Dialysis and Transplant Association - European Renal Association

174. Boronat A, Martinez-Huelamo M, Cobos A, de la Torre R. 2018. Wine and Olive Oil Phenolic Compounds Interaction in Humans. Diseases 6

175. He Y, Bai P, Gao S, Xu Y. 2018. The Marriage of An Ether-Based Electrolyte with Hard Carbon Anodes Creates Superior Sodium-Ion Batteries with High Mass Loading. ACS applied materials \& interfaces

176. Bahuguna BP, Saini LK, Sharma RO, Tiwari B. 2018. Hybrid functional calculations of electronic and thermoelectric properties of $\mathrm{GaS}, \mathrm{GaSe}$, and $\mathrm{GaTe}$ monolayers. Physical chemistry chemical physics : PCCP

177. Li X, Gao P, Tan J, Xiong K, Maitz MF, et al. 2018. Assembly of MetalPhenolic/Catecholamine Networks for Synergistically Anti-Inflammatory, Antimicrobial and Anticoagulant Coatings. ACS applied materials \& interfaces

178. Hartouni EP, Beeman B, Eckart MJ, Grim GP, Hatarik R, et al. 2018. Uncertainty analysis of response functions and gamma -backgrounds on Tion and t0 measurements from Cherenkov neutron detectors at the National Ignition Facility (NIF). The Review of scientific instruments 89:10I140

179. Lockard TE, Magee EW, Layne DA, Leutenegger MA, Eckart ME, et al. 2018. The Warm Electron Beam Ion Trap (WEBIT): An instrument for ground calibration of space-borne x-ray spectrometers. The Review of scientific instruments 89:10F124 
180. Dunne AE, Kawamatawong T, Fenwick PS, Davies CM, Tullett H, et al. 2018. Direct Inhibitory Effect of the Phosphodiesterase-4 Inhibitor, Roflumilast, on Neutrophil Migration in COPD. American journal of respiratory cell and molecular biology

181. Zainul R, Alif A, Aziz H, Arief S. 2015. Photoelectrosplitting Water Mechanism at Carbon Electrode Surface using Indoor lights.

182. Fédération nationale des déportés et internés résistants et patriotes (France)., Ecritures et pratiques dans les prisons et les camps de concentration nazis :, Musée des beaux-arts (Reims France)., Université de Reims ChampagneArdenne. 1996. Créer pour survivre: actes du colloque international "Ecritures et pratiques dans les prisons et les camps de concentration nazis" organisé à Reims les 20, 21 et 22 septembre 1995, par l'Université de Reims Champagne Ardenne et la Fédération Nationale des Déportés et Internés Résistants et Patriotes (FNDIRP). Paris: Fédération Nationale des Déportés et Internés Résistants et Patriotes. 263 s. pp.

183. Linda R, Ef. kommission. studies. evolution of concentration and competition series a44. 1979. International sectoral comparisons including analyses on the beverages industries in germany and europe, 1. Luxembourg,. $270 \mathrm{~s}$. pp.

184. Marfels C, Ef. kommission. studies. evolution of concentration and competition series b44. 1979. International sectoral comparisons including analyses on the beverages industries in germany and europe. 2. Luxembourg,. 137 s. pp.

185. Symposium on Media Concentration :, USA. Federal Trade Commission. Bureau of Competition. 1979. Proceedings of the Symposium on Media Concentration : december 14 and 15, 1978. Washington, D.C.: Bureau of Competition, Federal Trade Commission. bd. pp.

186. Fanelli A, Sorella MC, Ghisi D. 2018. Morphine sulfate abuse-deterrent formulations for the treatment of chronic pain. Expert review of clinical pharmacology

187. Campuzano IDG, Sobott F, van Stipdonk MJ. 2018. Editorial and Review: 30th ASMS Sanibel Conference on Mass Spectrometry-Computational Modelling in Mass Spectrometry and Ion Mobility: Methods for Ion Structure and Reactivity Determination. Journal of the American Society for Mass Spectrometry

188. Dou M, Chouinard CD, Zhu Y, Nagy G, Liyu AV, et al. 2018. Nanowellmediated multidimensional separations combining nanoLC with SLIM IM-MS for rapid, high-peak-capacity proteomic analyses. Analytical and bioanalytical chemistry

189. Abercrombie N, Warde A, Deem R. 2000. Contemporary British society. Cambridge: Polity Press. xx, 602 s. pp.

190. Arber S, Attias-Donfut C. 2001. The myth of generational conflict: the family and state in ageing societies. London: Routledge. xii, 232 s. pp.

191. Dunn JA. 1998. Driving forces : the automobile, its enemies, and the politics of mobility. Washington: Brookings Institution Press. x, 230 s. pp.

192. Even Rasmussen L, Amternes og Kommunernes Forskningsinstitut. 2001. Mobility out of socially deprived residential areas. Kbh.: AKF. 71, 11 sider pp.

193. Hibbs J. 1993. On the move - : a market for mobility on the roads. London: Institute of Economic Affairs. 95 s. pp.

194. Kahlenberg RD. 2000. A notion at risk: preserving public education as an engine for social mobility. New York: Century Foundation. vii, $356 \mathrm{~s}$. pp.

195. Savage M. 2000. Class analysis and social transformation. Buckingham: Open University Press. xvi, 185 s. pp.

196. Tassinopoulos A, Werner H, Kristensen S, Europæiske Center for Udvikling af Erhvervsuddannelse. 1998. Mobility and migration of labour in the European Union and their specific implications for young people. 
ThessalonikiLuxembourg: CEDEFOP ; Office for Official Publications of the European Communities. 126 sider. pp.

197. Ion DC. 1976. Availability of world energy resources : 1. supplement: coal, nuclear energy, natural gas. London: Graham \& Trotman. 104 s. pp.

198 Ion DC. 1978. Availability of world energy resources : second supplement. London: Graham \& Trotman. 112 s. pp.

199. The Rumanian Communist Party. Congress : 1965 (9.., Maurer IG, Stoica C, Apostol G. 1965. Report on the directives of the ninth congress of the Rumanian Communist Partry on the plan for the development of the national economy in the 1966-1970 period : july 20, 1965. Bucharest,: Agerpres. 104 s. pp.

200. Cole P, Hermon G, Huang CTJ. 2001. Long-distance reflexives. San Diego, Calif.: Academic. xlvii, 378 s. pp.

201. Harry K. 1985. Distance education in Western Europe : a selective annotated bibliography of current literature. Luxembourg: Office for Official Publications of the European Communities. 174 s. pp.

202. Hogarth T, Daniel WW, Policy Studies Institute. 1988. Britain's new industrial gypsies : long distance weekly commuters. London: Policy Studies Institute. $93 \mathrm{~s}$. pp.

203. Hollings D, Inwood H, Sheldon R, Economist Intelligence Unit. 1991. European railways : prospects for long distance passenger services in the 1990s. London: EIU, The Economist Intelligence Unit. 155 s. pp.

204. Holmberg B. 1977. Distance education : a survey and bibliography. London: Kogan Page. 167 s. pp.

205. Leth T, Danmark. Levnedsmiddelstyrelsen. Centrallaboratoriet. Afdeling A., Danmark. Levnedsmiddelstyrelsen. 1986. Kartoflers indhold af noeringsstoffer og nitrat : planteafstand, optagningstidspunkt og gødskning $=$ The nutrient and nitrate content in potatoes. Søborg Kbh.: Centrallaboratoriets afdeling Aeksp. DBK. 30 sider pp.

206. Maddux CD. 1992. Distance education : a selected bibliography. Englewood Cliffs, N.J.: Educational Technology Publications. 71 bl. pp.

207. Marantz A, Miyashita Y, O'Neil W, Mind Articulation Project Symposium. 2000. Image, language, brain : papers from the First Mind Articulation Project Symposium. Cambridge, Mass.: MIT Press. x, 272 s. pp.

208. Mead M, Métraux R. 2000. The study of culture at a distance. New York: Berghahn Books. xxxiv, 541 s. pp.

209. Odde Sørensen D. 1992. Massekultur mellem distance og beherskelse : om massen, det sociale og identitet i det moderne. Konferensspeciale. Københavns Universitet, Kbh. 112 s. pp.

210. Heller J, Vogel S. 1986. No laughing matter. London: Jonathan Cape. 335 s. pp.

211. High-Level Group "The European High-Speed Train Network". 1995. L'Europe à grande vitesse $=$ High-speed Europe $=$ Hochgeschwindigkeit Europa .

Luxembourg: Office for Official Publications of the European Communities. 168 s. pp.

212. Kowalik JS, NATO Advanced Research Workshop on High-Speed Computation :, North American Treaty Organization. Scientific Affairs Division. 1984. Highspeed computation. Berlin: Springer. 441 s. pp.

213. Speed K. 1982. Sea change: the battle for the Falklands and the future of Britain's navy. Bath: Ashgrove Press. 194 s., tav. pp.

214. Speed R. 1979. Strategic deterrence in the 1980s. Stanford, Calif.: Hoover Institution Press. 174 s. pp. 
215. Kemp AIS. 2018. Early earth geodynamics: cross examining the geological testimony. Philosophical transactions. Series A, Mathematical, physical, and engineering sciences 376

216. Liu P, Ptacek CJ, Blowes DW. 2018. Mercury Complexation with Dissolved Organic Matter Released from Thirty-Six Types of Biochar. Bulletin of environmental contamination and toxicology

217. Ricard TC, Haycraft C, Iyengar SS. 2018. Adaptive, Geometric Networks for Efficient Coarse-Grained Ab Initio Molecular Dynamics with Post-Hartree-Fock Accuracy. Journal of chemical theory and computation 14:2852-66

218. Ge R, Zhu W, Wilde SA, Wu H. 2018. Remnants of Eoarchean continental crust derived from a subducted proto-arc. Science advances 4:eaao3159

219. Chen Y, Xu W, Zhu H, Wei D, He F, et al. 2018. Effect of turbidity on micropollutant removal and membrane fouling by MIEX/ultrafiltration hybrid process. Chemosphere 216:488-98

220. Yuan T, Yang T, Chen H, Fu D, Hu Y, et al. 2018. New insights into oxidative stress and inflammation during diabetes mellitus-accelerated atherosclerosis.

Redox biology 20:247-60

221. Ferrer AMG, del Val NJ, Ianniciello C, Critical Cartography of Art and Visuality in the Global Age :. 2014. Critical cartography of art and visuality in the global age. Newcastle upon Tyne: Cambridge Scholars Publishing. 352 s. pp.

222. Zainul, R., \& Prima, C. B. (2017, June 29). Desain Geometri Sel PV. https://doi.org/10.31227/osf.io/7n8t4

223. Zainul, R. (2016, December 18). Design and Modification of Copper Oxide Electrodes for Improving Conversion Coefficient Indoors Lights (PV-Cell) Photocells. https://doi.org/10.31227/osf.io/pgn84

224. Zainul, R. (2016, September 24). Determination of the half-life and the quantum yield of $\mathrm{ZnO}$ semiconductor photocatalyst in humic acid. https://doi.org/10.31227/osf.io/e8a9x

225. Febriani, S. S., Yolanda, T., Arianti, V. A., \& Zainul, R. (2018, September 2). A Review Solid Stated : Principles and Methode. https://doi.org/10.31227/osf.io/7us4x

226. Liza, Y. M., Yasin, R. C., Maidani, S. S., \& Zainul, R. (2018, September 29). Sol Gel : Principle And Technique (A Review). https://doi.org/10.31227/osf.io/2cuh8

227. Zainul, R. (2016, November 19). Effect of Temperature and Particle Motion against the ability of $\mathrm{ZnO}$ Semiconductor Photocatalyst in Humic Acid. https://doi.org/10.31227/osf.io/wnygb

228. Dinata, A. A., Rosyadi, A. M., Hamid, S., \& Zainul, R. (2018, August 31). A Review Chemical Vapor Deposition : Process And Application. https://doi.org/10.31227/osf.io/yfeau

229. Putri, D. F., Ritonga, H. M., Murdiati, V., \& Zainul, R. (2018, August 31). A Review What Is Hydrothermal ?. https://doi.org/10.31227/osf.io/dm56c

230. Awalliyah, A., Ikhwan, H., Nugiasari, V., \& Zainul, R. (2018, August 31). A Review Prinsip Dasar Milling Dalam Sintesis Material. https://doi.org/10.31227/osf.io/9xsqe

231. Candani, D., Ulfah, M., Noviana, W., \& Zainul, R. (2018, September 1). A Review Pemanfaatan Teknologi Sonikasi. https://doi.org/10.31227/osf.io/uxknv

232. Fatimah, P., Jumalia, R., Novianti, E. R., \& Zainul, R. (2018, August 31). A REVIEW Teknik Blended : Prinsip dan Dasar-Dasar. https://doi.org/10.31227/osf.io/tm2w4

233. Zainul, R., Oktavia, B., Dewata, I., \& efendi, j. (2017, February 4). Studi Dinamika Molekular dan Kinetika Reaksi pada Pembelahan Molekul Air untuk Produksi Gas Hidrogen. https://doi.org/10.31227/osf.io/876s3 
234. Zainul, R., Alif, A., Aziz, H., Arief, S., \& s. (2015, October 22). Photoelectrosplitting Water Mechanism at Carbon Electrode Surface using Indoor lights. https://doi.org/10.31227/osf.io/vexq8

235. Zainul, R., Alif, A., Aziz, H., Arief, S., \& s. (2015, October 22). Photoelectrosplitting Water Mechanism at Carbon Electrode Surface using Indoor lights. https://doi.org/10.31227/osf.io/vcxq8

236. M., Yani, S. R., \& Zainul, R. (2017, September 4). Aktivasi Tanah Napa dan Pengaruhnya Terhadap Adsorpsi Ion Timbal (II)/ $\mathrm{Pb} 2+$. https://doi.org/10.31227/osf.io/ps523

237. P, O. M., A, L. G., S, A. Y. M., \& Zainul, R. (2018, September 1). A Review Grinding : Teknik dan Prinsip Dasar pada Pengolahan Material. https://doi.org/10.31227/osf.io/trv4q

238. H., Sanjaya, H., \& Zainul, R. (2016, August 30). Synthesis and Electrical Properties of ZnO-I TO and Al-ITO thin Film by Spin Coating Technique Through Sol Gel Process. https://doi.org/10.31227/osf.io/unrt4

239. M., Sanjaya, H., \& Zainul, R. (2015, December 30). Characterization of napa soil and adsorption of $\mathrm{Pb}$ (II) from aqueous solutions using on column method. https://doi.org/10.31227/osf.io/t8fh9

240. chaidir, z., Fadjria, N., A., \& Zainul, R. (2016, December 5). Isolation And Molecular Identification Of Freshwater Microalgae In Maninjau Lake West Sumatera. https://doi.org/10.31227/osf.io/nbcuf

241. chaidir, z., Zainul, R., Nurakhbari, D., \& Salim, M. (2016, September 24). Optimization of Spirulina Platensis Culture for Antioxidant Production. https://doi.org/10.17605/OSF.IO/FD6E4

242. zainul R, Oktavia B, Dewata I, Efendi J. Thermal and Surface Evaluation on The Process of Forming a $\mathrm{Cu} 2 \mathrm{O} / \mathrm{CuO}$ Semiconductor Photocatalyst on a Thin Copper Plate. Proc. IOP Conference Series: Materials Science and Engineering, 2018, 335:012039: IOP Publishing

243. Zainul R, Alif A, Aziz H, Arief S, Dradjad S, Munaf E. 2015. Design of photovoltaic cell with copper oxide electrode by using indoor lights. Research Journal Of Pharmaceutical Biological And Chemical Sciences 6:353-61

244. Mawardi M, Deyundha D, Zainul R. Characterization of PCC Cement by Addition of Napa Soil from Subdistrict Sarilamak 50 Kota District as Alternative Additional Material for Semen Padang. Proc. IOP Conference Series: Materials Science and Engineering, 2018, 335:012034: IOP Publishing

245. Anhar A, Sumarmin R, Zainul R. 2016. Measurement of Glycemic Index of West Sumatera Local Rice Genotypes for Healthy Food Selection. https://doi.org/10.31227/osf.io/tgy8h

246. Zainul R, Dewata I. 2015. Determination of $\mathrm{pH}-\mathrm{BOD}-\mathrm{COD}$ and degradation in batang arau watersheds at Padang city.https://doi.org/10.31227/osf.io/efdzi

1. 247. Zainul R, Alif A, Aziz H, Arief S. 2015. Disain Geometri Reaktor Fotosel Cahaya Ruang. Jurnal Riset Kimia 8:131 https://doi.org/10.25077/jrk.v8i2.230

248. Zainul R, Alif A, Aziz H, Arief S, Darajat S. 2015. Modifikasi dan Karakteristik IV Sel Fotovoltaik $\mathrm{Cu} 2 \mathrm{o} / \mathrm{Cu}-\mathrm{Gel} \mathrm{Na} 2 \mathrm{so} 4$ Melalui Iluminasi Lampu Neon. EKSAKTA 2:50

249. Yasthopi A. 2015. Photoelectrosplitting water for hydrogen production using illumination of indoor lights. Journal of Chemical and Pharmaceutical Research 7:246-56

250. Zainul R. 2015. Disain dan Modifikasi Kolektor dan Reflektor Cahaya pada Panel Sel Surya Al/Cu2O-Gel Na2SO4. http://repository.unp.ac.id/id/eprint/610 
251. Mawardi Anwar E, Kosela S, Wibowo W, Zainul R. 2015. Study of Pb (II) biosorption from aqueous solution using immobilized Spirogyra subsalsa biomass. Journal of Chemical and Pharmaceutical Research 7:715-22

252. Desy Kurniawati I, Harmiwati SS, Chaidir Z, Munaf E. Rahmiana Zein, Hermansyah Aziz, Rahadian Zainul. 2015. Biosorption of $\mathrm{Pb}$ (II) from Aqueous Solutions Using Column Method by Lengkeng (Euphoria logan lour) Seed and Shell. Journal of Chemical and Pharmaceutical Research 7:872-7

253. Zainul R, Nurakhbari D, Salim M. Optimization of Spirulina Platensis Culture for Antioxidant Production. https://doi.org/10.17605/OSF.IO/FD6E4

254. Horiza, H., Azhar, M. and Efendi, J. (2017) "Ekstraksi Dan Karakterisasi Inulin Dari Umbi Dahlia (Dahlia Sp.L) Segar Dan Disimpan", Eksakta: Berkala Ilmiah Bidang MIPA, 18(01), pp. 31-39. doi: https://doi.org/10.24036/eksakta/vol18iss01/14.

255. Iryani, I., Iswendi, I. and Katrina, I. T. (2017) "Uji Aktivitas Anti Diabetes Mellitus Senyawa Metabolit Sekunder Fraksi Air Dari Beras Ketan Hitam ( Oryza Satival. Var Glutinosa) Pada Mencit Putih", Eksakta: Berkala Ilmiah Bidang MIPA, 18(01), pp. 54-60. doi: https://doi.org/10.24036/eksakta/vol18$\underline{\text { iss01/17. }}$.

256. Suryelita, S., Etika, S. B. and Kurnia, N. S. (2017) "Isolasi Dan Karakterisasi Senyawa Steroid Dari Daun Cemara Natal (Cupressus funebris Endl.)", Eksakta: Berkala Ilmiah Bidang MIPA, 18(01), pp. 86-94. doi: https://doi.org/10.24036/eksakta/vol18-iss01/23.

257. Iskandar, I., Horiza, H. and Fauzi, N. (2017) "Efektivitas Bubuk Biji Pepaya (Carica Papaya Linnaeaus) Sebagai Larvasida Alami Terhadap Kematian Larva Aedes Aegypty Tahun 2015”, Eksakta: Berkala Ilmiah Bidang MIPA, 18(01), pp. 12-18. doi: https://doi.org/10.24036/eksakta/vol18-iss01/12.

258. Ramli, R., Jonuarti, R. and Hartono, A. (2017) "Analisis Struktur Nano Dari Lapisan Tipis Cobalt Ferrite Yang Dipreparasi Dengan Metode Sputtering", Eksakta: Berkala Ilmiah Bidang MIPA, 18(01), pp. 46-53. doi: https://doi.org/10.24036/eksakta/vol18-iss01/16.

259. Sanjaya, H. (2017) "Degradasi Methylene Blue Menggunakan Katalis Zno-Peg Dengan Metode Fotosonolisis", Eksakta: Berkala Ilmiah Bidang MIPA, 18(02), pp. 21-29. doi: https://doi.org/10.24036/eksakta/vol18-iss02/45.

260. Ningsih, S. K. (2017) "Sintesis Dan Karakterisasi Nanopartikel Zno Doped Cu2+ Melalui Metoda Sol-Gel”, Eksakta: Berkala Ilmiah Bidang MIPA, 18(02), pp. 3951. doi: https://doi.org/10.24036/eksakta/vol18-iss02/51.

261. Saiya, A. (2017) "Analisis Residu Klorpirifos Dalam Sayuran Kubis Dengan Metode Hplc Di Beberapa Pasar Tradisional Di Sulawesi Utara”, Eksakta: Berkala Ilmiah Bidang MIPA, 18(02), pp. 77-85. doi: https://doi.org/10.24036/eksakta/vol18-iss02/57.

262. Syafei, N. (2017) "Analisa Fenomena Korosi Pelat Pipa Baja Karbon Api 51-X65 Dalam Larutan 250 Ml Asam Asetat Dan 4750 Ml Aquades Pada Kondisi Gas Co2 Dan H2s Jenuh Pada Suhu Ruang", Eksakta: Berkala Ilmiah Bidang MIPA, 18(02), pp. 113-120. doi: https://doi.org/10.24036/eksakta/vol18-iss02/63.

263. Tutuarima, T. (2017) "Sifat Fisik Dan Kimia Marmalade Jeruk Kalamansi (Citrus microcarpa) : Kajian Konsentrasi Pektin Dan Sukrosa Physical and Chemical Properties of Marmalade Citrus of Calamondin (Citrus microcarpa) : Study of Pectin and Sucrose Concentrations", Eksakta: Berkala Ilmiah Bidang MIPA, 18(02), pp. 164-172. doi: https://doi.org/10.24036/eksakta/vol18-iss02/73.

264. Ruswandi, R. (2018) "Determination of Fructose Content resulted by Inulin Hydrolysis with DNS as Oxidizer", Eksakta: Berkala Ilmiah Bidang MIPA, 19(1), pp. 14-23. doi: https://doi.org/10.24036/eksakta/vol19-iss1/102. 
265. Sanjaya, H. (2018) "Degradasi Metil Violet Menggunakan Katalis Zno-Tio2 Secara Fotosonolisis", Eksakta: Berkala Ilmiah Bidang MIPA, 19(1), pp. 91-99. doi: https://doi.org/10.24036/eksakta/vol19-iss1/131.

266. Hidayani, T. (2018) "Grafting Polipropilena Dengan Maleat Anhidrida Sebagai Pengikat Silang Dengan Inisiator Benzoil Peroksida", Eksakta: Berkala Ilmiah Bidang MIPA, 19(1), pp. 56-62. doi: https://doi.org/10.24036/eksakta/vol19iss $1 / 127$.

267. Prabowo, H. (2018) "Penyelidikan Kelayakan Kimia Dan Penyebaran Cadangan Pasir Besi Daerah Tiku Kabupaten Agam Untuk Bahan Baku Semen Pada Pt. Semen Padang”, Eksakta: Berkala Ilmiah Bidang MIPA, 19(1), pp. 39-42. doi: https://doi.org/10.24036/eksakta/vol19-iss1/121.

268. Syafei, N. (2018) "Riset Material Analisa Fenomena Korosi Pelat Pipa Baja Karbon Api 51-X65 Dalam Larutan 7900 Ml Air Laut Dan 100 Ml Amoniak Pada Kondisi Gas Co2 Dan H2s Jenuh Pada Suhu Ruang.", Eksakta: Berkala Ilmiah Bidang MIPA, 19(1), pp. 7-13. doi: https://doi.org/10.24036/eksakta/vol19iss $1 / 83$.

269. Parbuntari, H., Prestica, Y., Gunawan, R., Nurman, M. and Adella, F. (2018) "Preliminary Phytochemical Screening (Qualitative Analysis) of Cacao Leaves (Theobroma cacao L.)", Eksakta: Berkala Ilmiah Bidang MIPA, 19(2), pp. 40-45. doi: https://doi.org/10.24036/eksakta/vol19-iss2/142.

270. Dinata, M. and Soehardi, F. (2018) "Factor Analysis of Physics Chemistry Waters that Affects Damage Safety Cliff on the Outskirts of River Siak", Eksakta: Berkala Ilmiah Bidang MIPA, 19(2), pp. 46-49. doi: https://doi.org/10.24036/eksakta/vol19-iss2/143.

271. Sofyanita, S. and Octaria, Z. (2018) "Fenthion Compound Degradation in the Pesticide Bayleton $500 \mathrm{ec}$ in Sonolysis, Ozonolysis and Sonozolysis with Addition of TiO2-anatase", Eksakta: Berkala Ilmiah Bidang MIPA, 19(2), pp. 7079. doi: https://doi.org/10.24036/eksakta/vol19-iss2/153.

272. Harahap, F. and Lubis, L. (2018) "Analysis of Heavy Metals Distribution in the River Town of Hamasaki's Rod Padangsidimpuan", Eksakta: Berkala Ilmiah Bidang MIPA, 19(2), pp. 50-56. doi: https://doi.org/10.24036/eksakta/vol19$\underline{\text { iss2/149. }}$.

273. Syafei, N., Hidayat, D., Emilliano, E. and Men, L. (2018) "Analysis Cracking Corrosion on Carbon Steel Pipes API 5L-X65 In Solution $7700 \mathrm{ml}$ Aquades, 250 $\mathrm{ml}$ Acetic Acid and $50 \mathrm{ml}$ Ammonia with Gas $\mathrm{CO} 2$ and $\mathrm{H} 2 \mathrm{~S}$ in Saturation Condition", EKSAKTA: Berkala Ilmiah Bidang MIPA, 19(2), pp. 21-31. doi: https://doi.org/10.24036/eksakta/vol19-iss2/138. 